\title{
Acoustic Directivity of the DGEN Aero-propulsion Research Turbofan at Multiple Farfield Array Locations
}

\author{
Daniel L. Sutliff* \\ NASA Glenn Research Center, Cleveland, Ohio, 44135
}

\begin{abstract}
The NASA Glenn Research Center's DGEN Aero-propulsion Research Turbofan (DART) is based on the Price Induction DGEN380 - a small, 500-lbf thrust class, high-bypass, geared-turbofan engine with a separate flow nozzle. The general characteristics of the DART make it an ideal candidate for utilization as a test bed for engine aeroacoustic research in a relevant performance environment. To provide a baseline acoustic profile for the DART, the system was tested in the NASA Glenn Research Center's Aero-Acoustic Propulsion Laboratory. Acoustic measurements from multiple external arrays locations were acquired over the nominal fan operating range of 50-95\%. The acoustic data are evaluated and reported in terms of overall, broadband, and tonal components. The existence of interaction tones (a result of the physics of the dual-spool interactions) are noted and presented. The symmetry of the acoustic directivity was measured in preparation for potential testing in other facilities.
\end{abstract}

\section{NOMENCLATURE}

$\begin{array}{llll}\text { AAPL } & - \text { Aero-Acoustic Propulsion Laboratory } & \text { RHS } & \text { - Right-Hand Side (of the engine) } \\ \text { DART } & - \text { DGEN Aero-propulsion Research Turbofan } & \text { RPM } & \text { - Revolutions-per-Minute } \\ \text { FADEC } & - \text { Full Authority Digital Electronic Control } & \text { OAPSL } & \text { - Overall Sound Pressure Level } \\ \text { LHS } & - \text { Left-Hand Side (of the engine) } & \text { PWL } & \text { - Acoustic Power Level } \\ \text { LSWT } & - \text { Low Speed Wind Tunnel } & \text { SPL } & \text { - Sound Pressure Level }\end{array}$

\section{INTRODUCTION}

$\mathrm{T}_{\mathrm{R}}^{\mathrm{H}}$ He Price Induction DGEN380 turbofan engine is the primary component integrated into the NASA Glenn Research Center's DGEN Aero-propulsion Research Turbofan (DART) system. It serves as a flexible, relevant, experimental aero-acoustic and aero-performance test bed and can provide valuable information throughout NASA's technology maturation process.

The DGEN380 engine is a high by-pass ratio turbofan engine proposed and designed for powering small personal light jets. It is optimized for a cruise altitude of about 10,000 ft $(3048 \mathrm{~m})$ and Mach 0.35 . It is built by the Price Induction Company situated in France and is capable of producing thrust up to about $575 \mathrm{lb}_{\mathrm{f}}(2580 \mathrm{~N})$. The engine features a two-spool flow architecture with a 3.32 ratio gearbox that links the low-pressure turbine to the fan spool. The high-pressure turbine runs the compressor and reaches rotational speeds up to about 50,000 revolutions per minute (RPM).

In order to baseline the acoustic characteristics of the DART, a series of tests were performed. Acoustic data were acquired from multiple microphone arrays: a circular array at constant radius, height, and azimuthal angle, and a linear array of constant distance from the engine centerline and also of constant height. A third array, an overhead array, at a greater distance than the other two, but of varying radius, height, and azimuthal angle, is reported in a companion paper. The acquired time histories were processed technique to separate the tone and broadband noise components of the raw acoustic test data.

An earlier ${ }^{1}$ paper documented the acoustic characteristics of the DGEN380 in a truck-mounted configuration, which was used for the initial acoustic signature evaluation. A systems analysis of the DGEN380 was presented in reference [2].

\footnotetext{
* Aerospace Engineer, Acoustics Branch, 21000 Brookpark Rd MS 54-3, Associate Fellow.
} 


\section{EXPERIMENTAL SETUP}

\section{A. AAPL Facility}

The AAPL dome ${ }^{3}$ is 65 -feet high and 130 -feet in diameter, providing an anechoic testing environment for engine component research and development. To provide an anechoic environment, custom-designed 2-foot thick fiberglass wedges are mounted on the dome's interior walls and floor areas adjacent to the test rigs. These wedges provide an anechoic environment down to $125 \mathrm{~Hz}$. Figure 1 shows a photo of the AAPL facility from the outside looking in.

\section{B. DGEN380 Turbofan Engine}

The DGEN380 is a geared two-spool unmixed-flow turbofan, with a maximum static thrust of $560 \mathrm{lb}$ ( $250 \mathrm{daN})$, and a high bypass ratio (7.6). It is a small engine, with a length of 44.3" $(1.126 \mathrm{~m})$, a fan inlet diameter of 13.78" $(350 \mathrm{~mm})$, and a maximum diameter of 18.5 " $(0.469 \mathrm{~m})$ (at the exit plane of the bypass nozzle). It is designed to cater to the Personal Light Jet market (jets capable of seating from 2 to 5 passengers and cruise at an altitude of up to $25,000 \mathrm{ft}$ at a velocity of Mach 0.45$)$. The maximum takeoff weight is approximately $3,550 \mathrm{lb}(1,600 \mathrm{~kg})$, for a range of more than $450 \mathrm{Nm}$. At the design point $\left(10,000 \mathrm{ft}\right.$, $0.338 \mathrm{M \#}$, ISA), its thrust is $240 \mathrm{lb}_{\mathrm{f}}$ (107 daN) for a specific fuel consumption of $0.771 \mathrm{lbm} \mathrm{hr}^{-1} \mathrm{lb}_{\mathrm{f}}^{-1}\left(0.768 \mathrm{~kg} \mathrm{~h}^{-1} \mathrm{daN}^{-1}\right)$. The maximum overall pressure ratio is of 5.3 (1.2 from the fan, 4.6 from the centrifugal compressor). Figure 2 shows these dimensions of the DGEN380.

Among its unique features is the all-electric starter/generator. The high-pressure (HP) spool is equipped with a reversible electrical drive, enabling engine ignition and power generation for the aircraft's requirements. The lowpressure (LP) spool is equipped with a gearbox of reduction ratio 3.32, which enables the LP turbine to reach speeds close to 44,000 RPM, while the fan blade tip speed remains subsonic (fan diameter is equal to $0.350 \mathrm{~m}$ ). This allows for a more compact design. The HP spool speed reaches 52,000 RPM at takeoff power. Table I lists the blade/vane counts of these rotating sources.

The DGEN380 was integrated into the AAPL facility by mounting the engine and its associated pylon on a platform. Figure 3 is a schematic of the DART system showing the two locations where the DGEN380 component of DART can be located.

Initially, the FADEC automatic sweep was programmed to achieve 50\% through $90 \%$, then $95.6 \%$, return to $50 \%$, and then repeat the $95.6 \%$ corrected fan RPM set point. This $95.6 \%$ max speed (and repeat) was initially chosen based on this being the max continuous high-pressure turbine speed permitted at standard day conditions (higher HPT speeds would be time-limited for brief durations such as take-off). However, operating on hotter days, and the addition of an internal containment shield for the turbine tri-hub failure (extremely unlikely - but an additional safety requirement when operating in a research paradigm) resulted in the inability to reach $95.6 \%$ consistently (the internal shield reduced heat transfer from the high-pressure turbine resulting in a higher EGT). The automatic sweep was programmed to stop at a designated max-EGT, which often was lower than $95.6 \%$ After some analysis, the sweep was reprogrammed to add $92.5 \%$ as the consistently achievable point. (See Table II).

Another caveat (lesson learned) regarding the setting of the corrected fan speed is the temperature sensor used to correct the fan speed was located in an area that was exposed to a higher temperature than ambient, by about $2-3^{\circ} \mathrm{F}$, resulting in a corrected fan speed error $\sim 0.2 \%$. A more appropriate location for the temperature sensor should be used in the future.

\section{CONFIGURATIONS TESTED}

The primary location for the DART is in the side location (where the venerable $\mathrm{ANCF}^{4}$ was located). This location limits acoustic microphone arrays to the left-hand side (LHS) of the DART. All references to left/right are in the pilot frame of reference. Figure 4a shows the DART in the side location. The DART was also tested near the center of the AAPL facility in order to determine the acoustic symmetry (i.e. obtain the acoustic directivity from the right-hand-side (RHS) of DART). Figure $4 \mathrm{~b}$ shows the DART in this location and also shows the base the engine/pylon is mounted on. The placement of the center location also allowed for directivity comparisons of the close-in arrays to the overhead array ${ }^{5}$.

In addition, the effect of the pylon thrust lock-out mechanism was measured and documented. The pylon lockout is a small block that is used to prevent the engine from rotating. This feature can be utilized if rotation of the engine (due to thrust) is undesirable. Examples are when the inlet is extended and support is required due to excess weight $^{6}$, or potential use of the Rotating Rake. Obviously, in this configuration, thrust is not measured by the load cell. Table III provides a listing of the configurations tested, indicating the arrays utilized, and the thrust-lock out status. 


\section{EXTERNAL MICROPHONE ARRAYS}

Acoustic data were acquired from 30 microphones, which were located in several locations relative to the engine vertical centerline. The microphones in this arc were $1 / 4$ " -Electret-style PCB $^{\circledR}$ model $130 \mathrm{E} 20$ microphones. These microphones were TEDS $^{\circledR}$ capable current-supplied at $6 \mathrm{~mA}$.

Two arrays were utilized: (i) a circular arc at a constant radius, azimuthal angle, and centerline height; (ii) a linear arc, parallel to the engine centerline, with varying radius. Both arcs were installed on each side of the engine to measure the symmetry of the acoustic directivity.

The circular arc was in two segments; a forward arc centered about the inlet plane, and an aft arc centered about the bypass nozzle exit plane. Figure 5 shows this array relative to the DGEN380 location and Table IV lists the geometric information.

A linear array was also used to provide a baseline in anticipation of testing the DART in the NASA GRC 9x15 Foot LSWT, which uses linear traversing microphone 88 " from the centerline for obtaining acoustic measurements. Figure 6 and Table V provides the geometric location of the linear array microphones relative to the DGEN380. Figure 7 illustrates and defines the Left- and Right-Hand Sides. These definitions were based on the pilot seat.

The time-histories were acquired from the microphones in the arcs at a sampling frequency of $250 \mathrm{kHz}$ using a $40 \mathrm{~Hz}-50 \mathrm{kHz}$ band-pass filter on a HBM GEN2 $\mathrm{i}^{\circledR}$ data acquisition recorder. The acquisition time was 15 seconds at each condition.

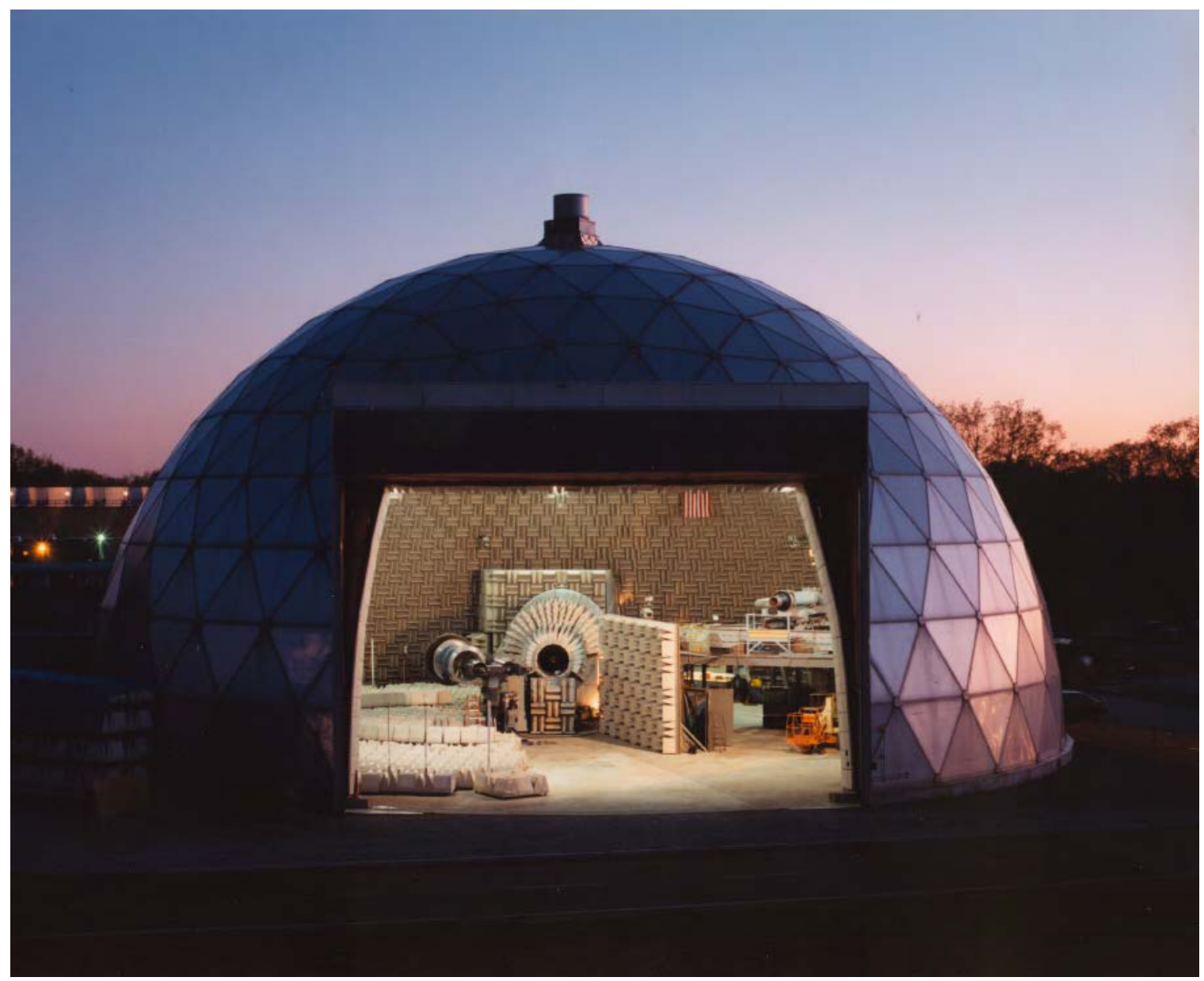

Figure 1. Aero-Acoustic Propulsion Laboratory 

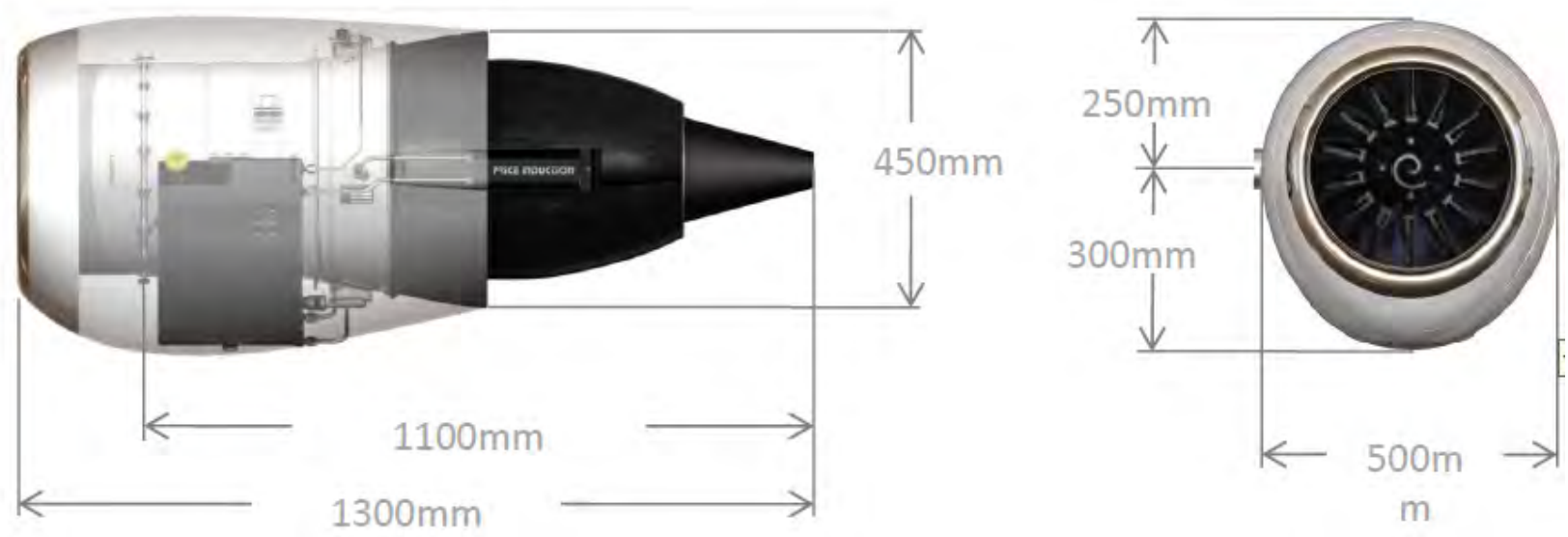

Figure 2. Price Induction DGEN380 Turbofan Engine Dimensions

TABLE I. DGEN380 Blade Counts.

\begin{tabular}{||c|c|c|}
\hline Component & Blades & Vanes \\
\hline Fan & 14 & 40 \\
\hline Compressor & 11 & 19 \\
\hline HP-Turbine & 38 & 19 \\
\hline LP-Turbine & 38 & 16 \\
\hline
\end{tabular}

Note:

Compressor and HP-turbine are coupled.

LP-turbine and fan are coupled by a 3.32 ratio gearbox.

TABLE II. DGEN380 Test Settings.

\begin{tabular}{||c||c||}
\hline NOMINAL & $\begin{array}{c}\text { RPMc-Fan } \\
(\mathbf{\%})\end{array}$ \\
\hline 1 & $i d l e$ \\
\hline 2 & $50 \%$ \\
\hline 3 & $60 \%$ \\
\hline 4 & $70 \%$ \\
\hline 5 & $80 \%$ \\
\hline 6 & $90 \%$ \\
\hline 7 & $92.5 \% \wedge$ \\
\hline 9 & $95.6 \% \star$ \\
\hline 10 & $50 \%$ \\
\hline 11 & $95.6 \% \star$ \\
\hline
\end{tabular}

Note: *Max Fan speed limited by HPT/EGT temperature limits Aadded $92.5 \%$.

TABLE III. Engine Configurations Tested

\section{DATE}

$$
\begin{gathered}
27 / 28-\text { Apr-17 } \\
4-\text { Aug-17 } \\
7 \text {-Aug-17 } \\
8 \text {-Aug-17 } \\
10-\text { Aug-17 } \\
11-\text { Aug-17 }
\end{gathered}
$$

\section{LOCATION}

Side

Center

Center

Center

Center

Center

\section{DGEN Config}

Baseline Inlet

Baseline Inlet

Baseline Inlet

Baseline Inlet

Baseline Inlet

Baseline Inlet
ARRAY

$10 \mathrm{ft}$ arc - LHS

$10 \mathrm{ft}$ arc - LHS

$10 \mathrm{ft}$ arc - LHS

$10 \mathrm{ft}$ arc - RHS

Linear Array- RHS

Linear Array- LHS
THRUST

ON

ON

Locked Out

Locked out

Locked Out

Locked out 


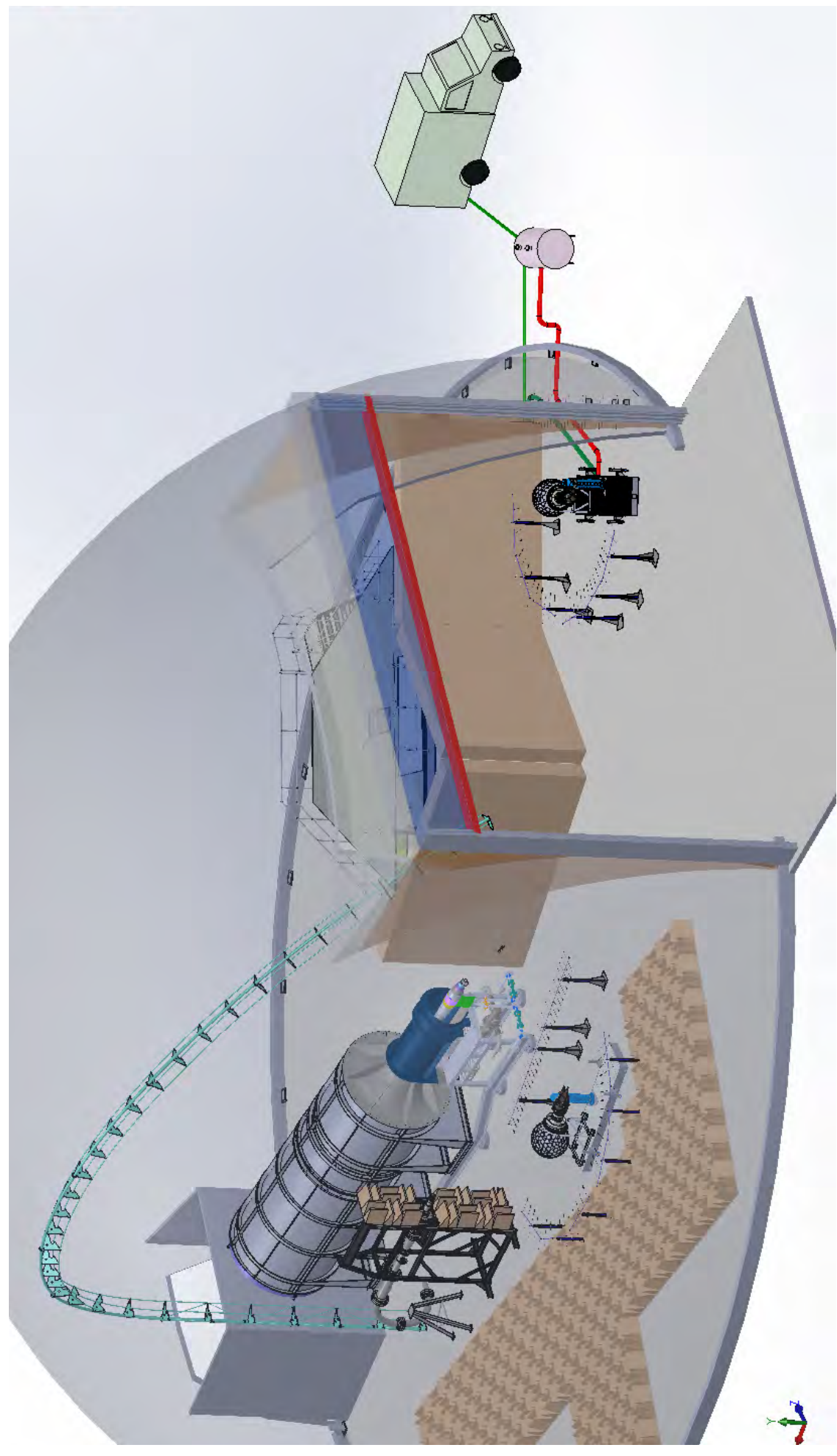

Figure 3. Schematic of DART in the Aero-Acoustic Propulsion Laboratory Showing the Two Test Locations 


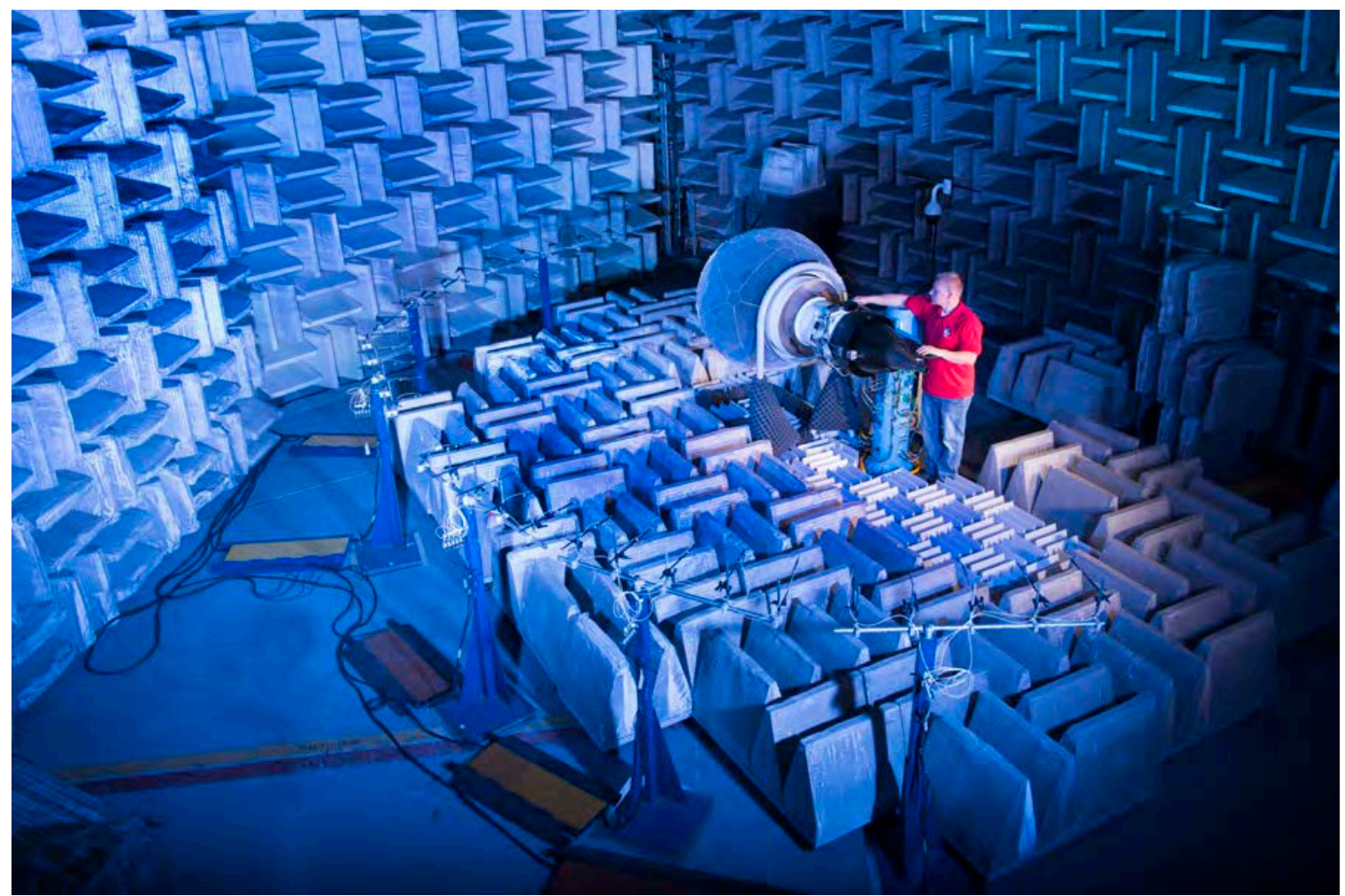

(a) Side Location with Circular Array on Left-Hand Side

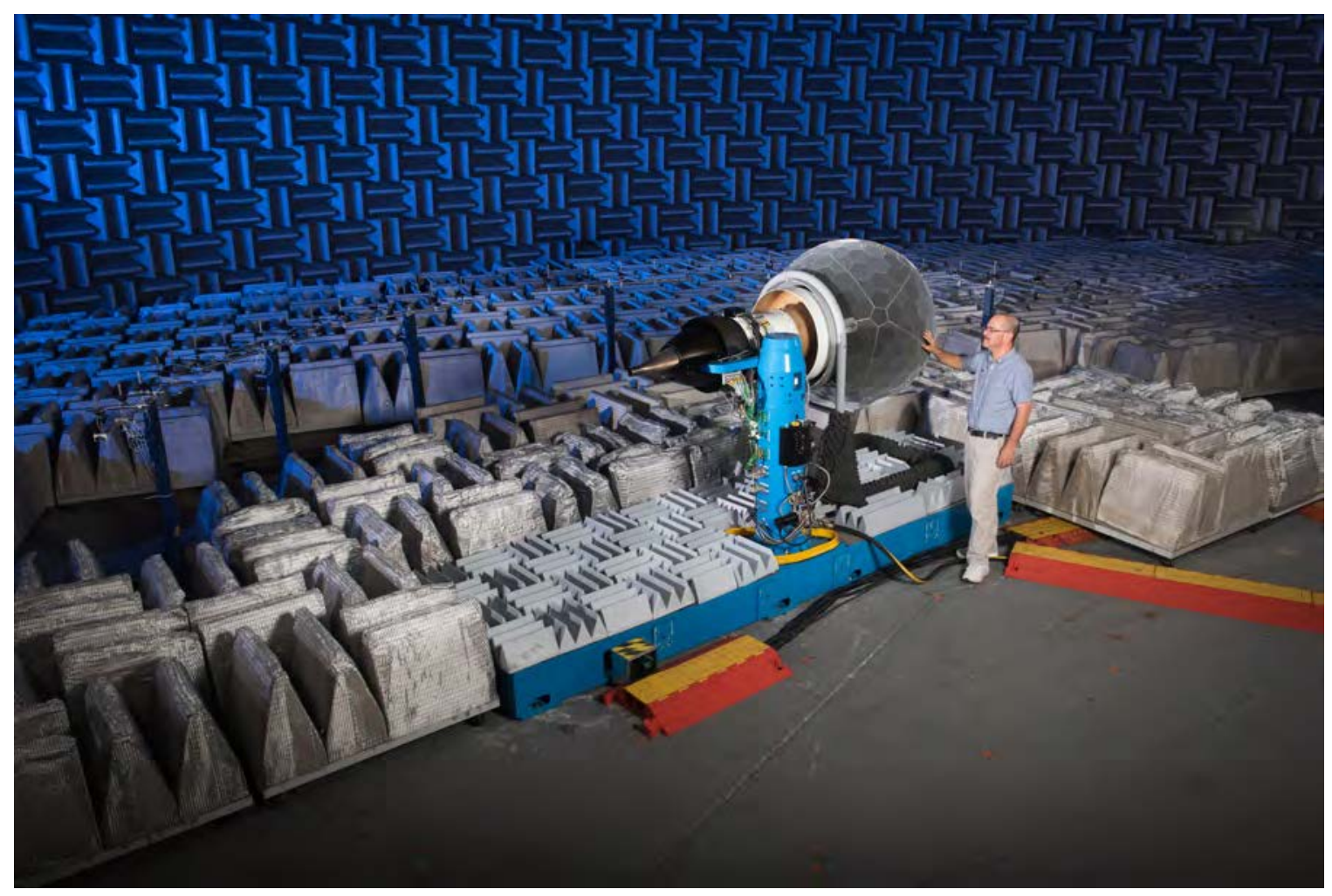

(b) Center Location with Circular Array on Left-Hand Side

Figure 4. Photos of DART in AAPL

6

American Institute of Aeronautics and Astronautics 
TABLE IV. Circular Microphone Array Geometry

\begin{tabular}{|c|c|c|c|}
\hline $\begin{array}{c}\text { Mic } \\
\#\end{array}$ & $\begin{array}{c}\text { Referenced } \\
\text { to Inlet } \\
\text { Plane* (deg) }\end{array}$ & $\begin{array}{c}\text { Mic } \\
\#\end{array}$ & $\begin{array}{l}\text { Referenced } \\
\text { to Exhaust } \\
\text { Plane (deg) }\end{array}$ \\
\hline 1 & 0 & 16 & 90.0 \\
\hline 2 & 6.4 & 17 & 95.0 \\
\hline 3 & 12.9 & 18 & 100.0 \\
\hline 4 & 19.3 & 19 & 105.0 \\
\hline 5 & 25.7 & 20 & 110.0 \\
\hline 6 & 32.1 & 21 & 115.0 \\
\hline 7 & 38.6 & 22 & 120.0 \\
\hline 8 & 45.0 & 23 & 125.0 \\
\hline 9 & 51.4 & 24 & 130.0 \\
\hline 10 & 57.9 & 25 & 135.0 \\
\hline 11 & 64.3 & 26 & 140.0 \\
\hline 12 & 70.7 & 27 & 145.0 \\
\hline 13 & 77.1 & 28 & 150.0 \\
\hline 14 & 83.6 & 29 & 155.0 \\
\hline 15 & 90.0 & 30 & 160.0 \\
\hline
\end{tabular}

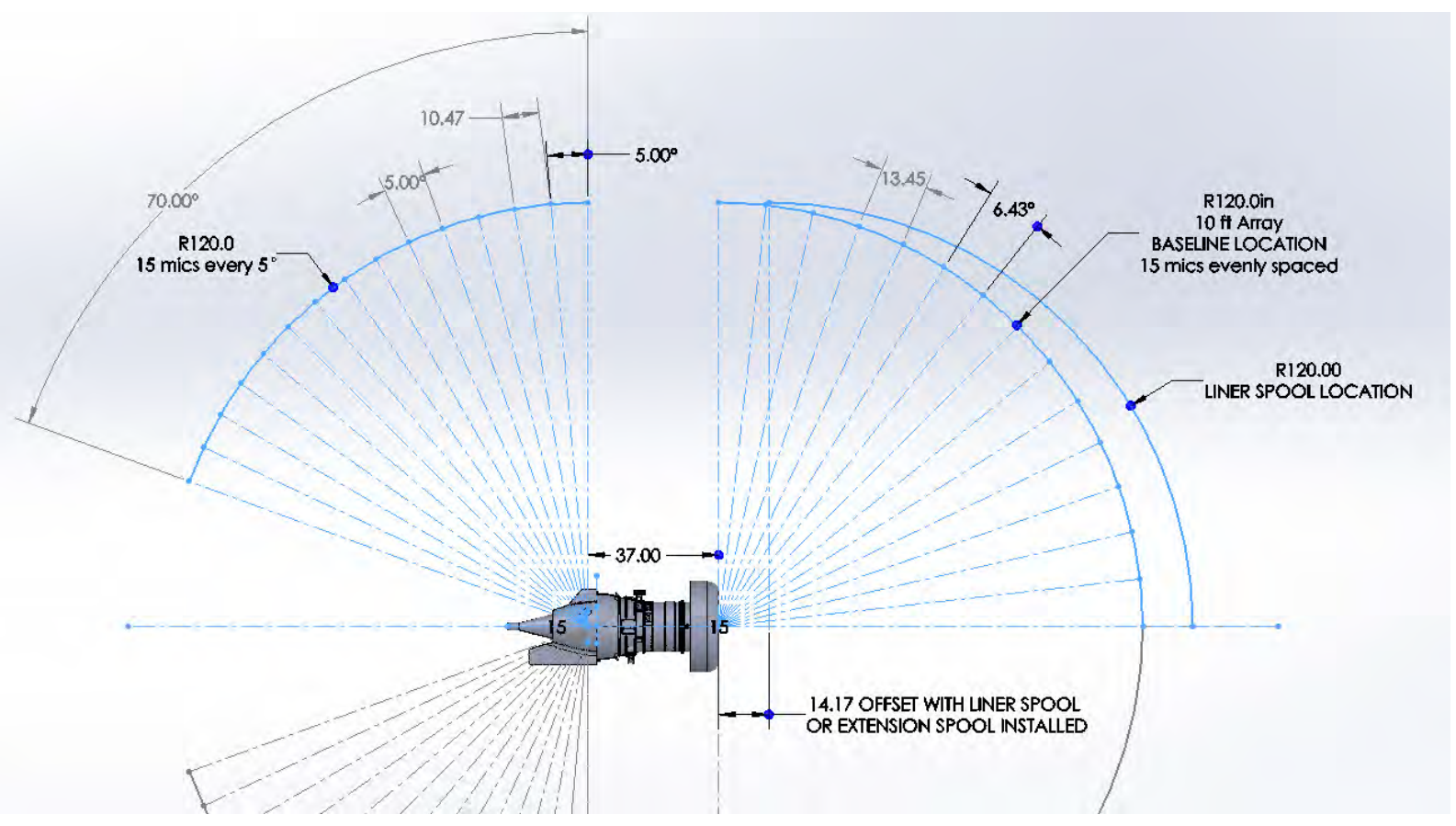

Figure 5. Circular Array about DGEN380 engine (shown on LHS) Note adjustment of forward arc as engine inlet is extended

American Institute of Aeronautics and Astronautics 


\section{TABLE V.}

\section{Linear Microphone}

Array Geometry

\begin{tabular}{|c|c|}
\hline Mic & Inches \\
\hline 1 & 0 \\
\hline 2 & 9.0 \\
\hline 3 & 17.9 \\
\hline 4 & 26.9 \\
\hline 5 & 35.9 \\
\hline 6 & 44.9 \\
\hline 7 & 53.8 \\
\hline 8 & 62.8 \\
\hline 9 & 71.8 \\
\hline 10 & 80.7 \\
\hline 11 & 89.7 \\
\hline 12 & 98.7 \\
\hline 13 & 107.6 \\
\hline 14 & 116.6 \\
\hline 15 & 125.6 \\
\hline 16 & 134.6 \\
\hline 17 & 143.5 \\
\hline 18 & 152.5 \\
\hline 19 & 161.5 \\
\hline 20 & 170.4 \\
\hline 21 & 179.4 \\
\hline 22 & 188.4 \\
\hline 23 & 197.3 \\
\hline 24 & 206.3 \\
\hline 25 & 215.3 \\
\hline 26 & 224.3 \\
\hline 27 & 233.2 \\
\hline 28 & 242.2 \\
\hline 29 & 251.2 \\
\hline 30 & 260.1 \\
\hline
\end{tabular}

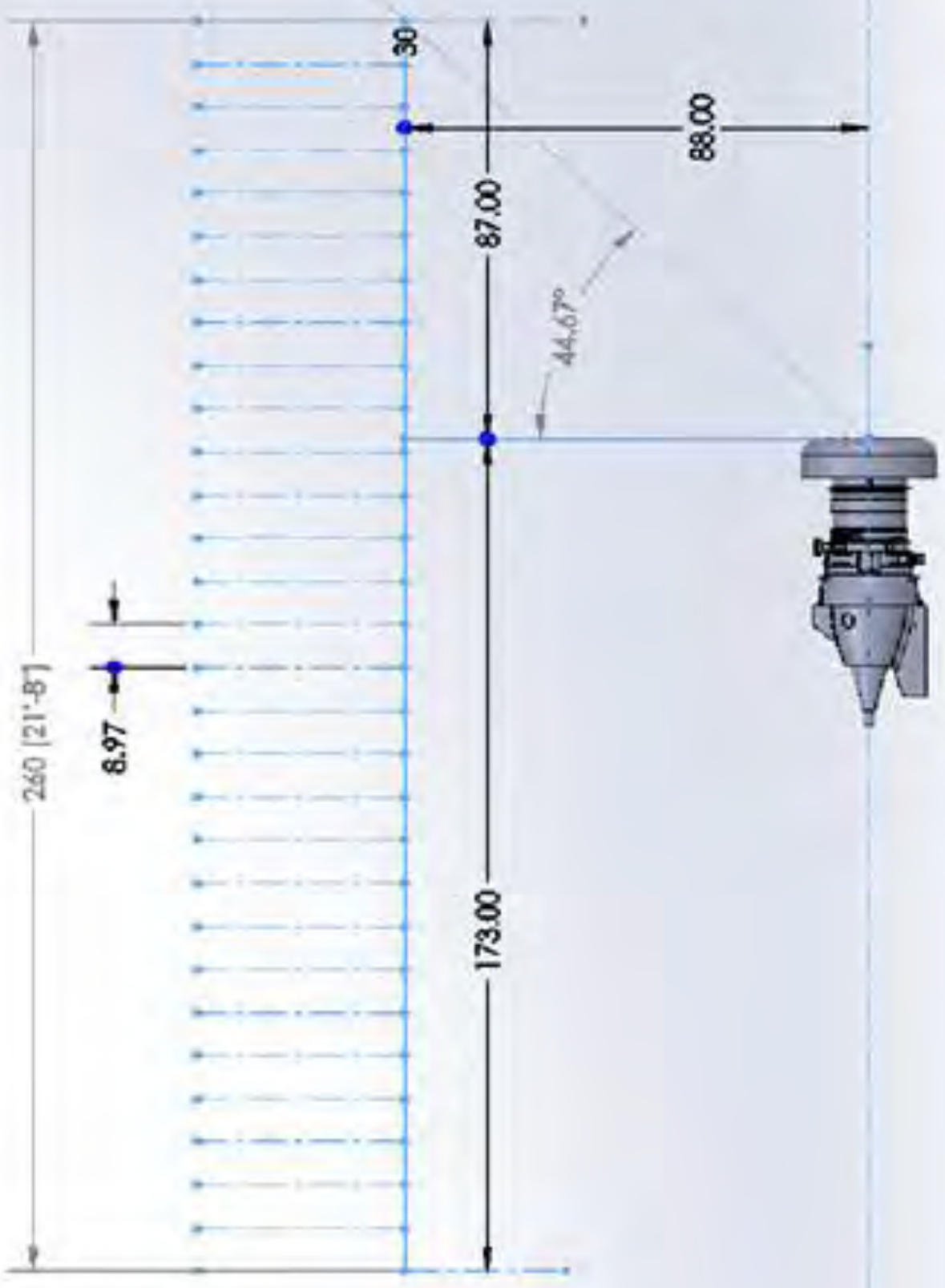

Figure 6. Linear Array about DGEN380 engine (shown on LHS) 

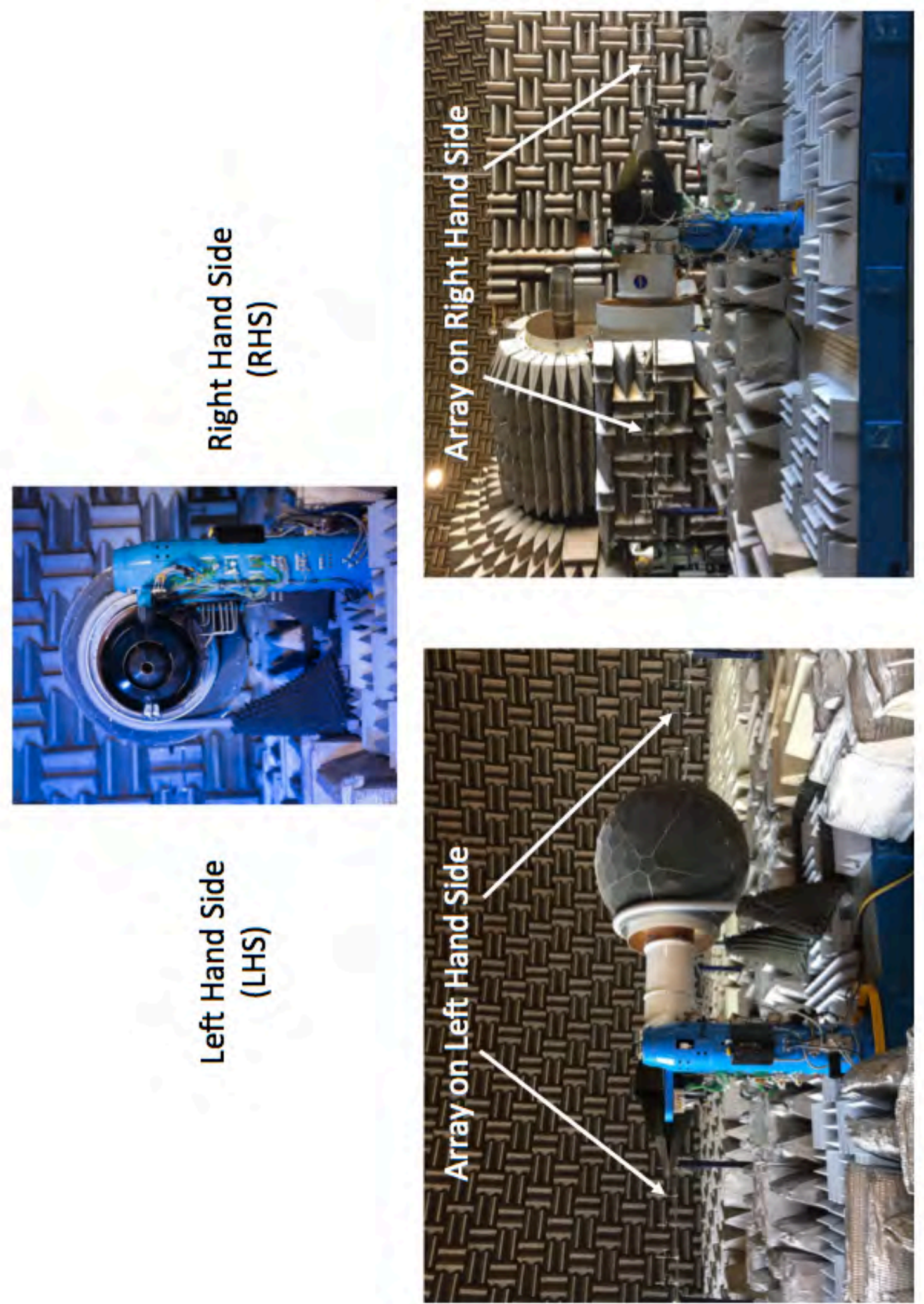

Figure 7. Arrays on Left- and Right-Hand Side of Engine 


\section{RESULTS}

\section{A. OVERALL}

The data as acquired from the 10' radius circular arc for each comparison of the configurations will be presented in this section. The data analysis method used in this work is based on the technique recently developed by Sree and Stephens ${ }^{7}$. The technique was developed to separate tone and broadband noise components from raw acoustic data generated from a hobby mini open-rotor having 4-forward and 3-aft blades, and a counter-rotating open-rotor model (F31A31) having 12 forward and 10 aft blades ${ }^{8}$.

When two noise sources rotating at different RPM are present, sum and difference tones are generated in addition to the harmonics of each source ${ }^{9,10}$. The DGEN380 has a dual-spool configuration; the spools are independent and therefore rotate at differing RPM. The high-speed spool connects the compressor and the highpressure turbine, each having a different blade count, and therefore differing fundamental blade pass frequencies. The low-speed spool connects the low-pressure turbine and the fan, but with a 3.32 gear reduction. This reduction, combined with the differing blade-count also results in substantially differing blade-passing fundamental frequencies (refer to Table I).

Figure 8 presents a sample comparison of the acoustic directivity as measured by the circular, constant radius microphone array for both the forward and aft quadrant arrays - refer back to Figure 5/Table IV. These spectra were obtained by averaging the 15 individual microphone spectra. This method was utilized in order to highlight the multitude of harmonic and interaction tones present - though these will vary at each angle. Multiple x-axes are included to aid in analysis. They present the frequency, normalization by the low-pressure shaft speed, and normalization by the high-pressure shaft speed.

The aft spectra sum (Figure 8a) shows the harmonic tonal components of the fan and compressor, with F1 and $\mathrm{C} 1$ again dominant. The fan/compressor interaction components are of significantly less strength - expected since any propagation would be at an extreme radiation angle or through the core. Also seen in the spectra is the lowpressure turbine fundamental (L1). This is at a low speed shaft order of 126.16 (38 blades x 3.32 gear ratio) or $25,665 \mathrm{~Hz}$. The high-pressure turbine fundamental (H1) is seen at the high-speed shaft order of $38(31,363 \mathrm{~Hz})$. In the aft, the fundamental tones of the turbines $(\mathrm{L} 1 / \mathrm{H1})$ are dominant and the typical hay-stacking from propagation through the two shear layers is visible in the spectra.

The forward spectra sum (Figure 8b) shows significant tonal components. The fan blade-passing fundamental (F1) at the low-pressure shaft order of $14(2,846 \mathrm{~Hz})$ is present, even though the rotor/stator count is such that it should be cut-off. This is potentially a result of the rotor/strut (\# of struts $=4$ ) interaction, which would be cut-on and has been noted to be present in turbofan engines ${ }^{11}$. The $2^{\text {nd }}$ fan harmonic is dominant, with F3-F10 noted to have decreasing amplitude, which is typical. The compressor fundamental (C1) at the high-pressure shaft order of 11 $(9,079 \mathrm{~Hz})$ is very strong, equal to that of F2. Multiple sum and difference interaction tones between the fan and compressor harmonics are seen. Significant are the $\mathrm{C} 1-\mathrm{F} 1$ and $\mathrm{C} 1+\mathrm{F}_{\mathrm{n}}$; for $\mathrm{n}=1$ to 7 . Likewise, the interaction of the compressor $2^{\text {nd }}$ harmonic and the $1^{\text {st }} 7$ fan harmonics are identifiable also with decreasing amplitude as the fan fundamental increases.

Although a formal repeatability study (multiple runs, back-to-back, at differing sweeps, days, etc.) is impractical, a few repeat points were acquired as part of the automatic sweep - with the caveat described in section II.B. Figures 9 and 10 show the spectral repeatability for individual representative mics, and Figures 13 through 15 show the repeatability of the directivity patterns for the 3 separated components of the spectra (overall, broadband, and tonal).

The spectral comparison acquired with DART at a fixed location is presented on Figure 9. In this mode the repeat points were separated only by a brief return to the 50\% RPM point. Figures $9 \mathrm{a}$ and $9 \mathrm{~b}$ show the spectra for an aft mic at $125^{\circ}$ and a forward mic at $38.6^{\circ}$ while the DART was in the side location; Figures $9 \mathrm{c}$ and $9 \mathrm{~d}$ show the spectra for an aft mic at $125^{\circ}$ and a forward mic at $38.6^{\circ}$ while the DART was in the center location. For these cases, the broadband levels are remarkably consistent at both locations. Some variation in the tone levels are seen. Figure 10 shows the spectra of the same two representative microphones, but this time comparing data acquired with the DART at the center location to the side location. There are 3 points to compare: two points on successive days at the side location, and one point at the center location. The two points acquired at the side location were set manually through the throttle. It was noted that this setting was not as precise as the automated sweep.

The tests at the different locations were separated by more than 3 months, and the inlet was disassembled/reassembled during an intermediate test ${ }^{6}$. Here, some shifting in the frequency is seen due to the differing temperature setting a different actual fan rpm so as to run at the same corrected fan RPM (92.5\%). Still, the 
spectra are remarkably similar. More variation in the tones is seen, as well as in the broadband component broadband - especially in the frequency region between the two turbine tones.

The acoustic directivity (SPL) repeatability of the 3 spectral components is plotted in polar fashion. The total SPL component is the top pair of graphs; the broadband component located in the center, and the tonal component is located on the bottom of the page. The aft microphone array is plotted on the left polar plot, and the forward microphone array on the right. Figure 11 clarifies the orientation of the polar plots relative to the engine and microphone array quadrants. As described in section IIB, the corrected fan speed of the repeat points varies.

The OASPL is obtained by integrating each of the spectral components (overall, broadband, and tonal) separately over the $100 \mathrm{~Hz}$ to $40 \mathrm{kHz}$ frequency range and is presented for both the aft (Figure 12a) and forward arrays (Figure 12b). The speed range was over 50-95\% corrected RPM of the fan. The repeat point at 94.3\% RPMcFan is included, showing nearly identical levels, and the $92.5 \%$ repeat point showing $\sim 1 \mathrm{~dB}$ difference. The OAPSL levels have a slight 'dip' over 90-95\% RPMC-Fan for each of the 3 components, then decreasing steadily with decreasing fan RPM. In general, the OAPSL tonal levels are greater than the broadband levels, slightly so at higher RPMs and more so at the lower fan RPM, especially in the aft; and the aft levels are higher than the inlet.

Figure 13 shows the directivity when DART (94.3\% RPMc-Fan) is located in the side area of AAPL. The aft dominance in levels is notable, $\sim 12-13 \mathrm{~dB}$ higher. The aft levels repeat to well within any measurement uncertainty. A very slight difference is seen in the weaker inlet arc, mostly due to variations in the tonal component.

Figure 14 shows the directivity when DART (93.1\% RPMc-Fan) is located in the center area of AAPL. The general trends remain, but a slight variation in the $<1 \mathrm{~dB}$ aft arc appears - approximately the measurement uncertainty ${ }^{12}$. The tonal component variation is similar.

The comparison of the acoustic directivity between the two locations is shown in Figure 15. There are 3 points to compare: two points on successive days at the side location, and one point at the center location. The variation (as in the individual microphone spectra) is more apparent, especially in the forward arc. It is still only slightly more than a $\mathrm{dB}$ variation. This may be due to operating at a different corrected fan RPM (i.e. low-speed spool shaft) and hence the high-speed shaft operating at a slightly differing ratio due to the temperature difference.

As mentioned above, there is a lockout provision on the pylon to prevent the engine from pivoting due to thrust. This pivoting causes and change in the angle centerline relative to the microphones of about $2-3^{\circ}$. A comparison of the acoustic directivity acquired with and with-out the thrust locked out is shown on Figure 16. There does not appear to be much difference in the directivity compared to the variations seen in other repeats.

\section{B. HARMONICS and INTERACTION TONES}

The technique developed by Sree can be used to delineate the tones (or any bandwidth). The bandwidth selected to extract individual tones was $+-/ 2$ bins above/below the computed frequency. The 1 st 4 fan-harmonics, the 1 st and 2nd compressor fundamentals, and the fundamental turbine tones are extracted in this manner to determine the acoustic directivity. For any pair of polar plots, the aft circular array is shown on the left side, and the forward circular array is shown on the right side of the pair. These data were acquired at $92.5 \%$ Fan RPMc.

The acoustic directivity of the 1st 4 fan-harmonics (F1,F2,F3, and F4) is plotted on Figure 17. (The radial axis has a consistent scale for comparison). The lobe pattern is clearly seen, more strongly in the aft. Again, the fan fundamental, while technically cut-off, is present, but at a level lower than that of the cut-on harmonics (F2 - F3). Multiple lobes are seen as there will be several radials cut-on.

The compressor and turbine tonal acoustic directivity is presented in Figure 18. (Note that the amplitude scale changes levels, though the delta of the scale is consistent). The compressor fundamental (C1-Figure 18a) is somewhat surprisingly stronger in the aft. This could be a result of reflection off the struts and/or fan. The $2^{\text {nd }}$ harmonic of the compressor (C2-Figure 18b) is somewhat weaker than the fundamental, but also aft dominated. Figure 18c and 18d present the fundamentals of the low- (L1) and high-pressure (H1) turbines, respectively. Not surprisingly, the turbine tones are strongly aft dominated.

The acoustic directivity of the compressor/fan interactions is shown on Figure 19a (C1-F1) and Figure 19b $(\mathrm{C} 1+\mathrm{F} 1)$ and of the compressor fundamental with the fan $2^{\text {nd }}$ harmonic on Figure 19c $(\mathrm{C} 1-\mathrm{F} 2)$ and Figure $19 \mathrm{~d}$ $(\mathrm{C} 1+\mathrm{F} 2)$. The interaction of the compressor $2^{\text {nd }}$ harmonic with the fan fundamental is shown on Figure 20a (C2-F1) and Figure 20b $(\mathrm{C} 2+\mathrm{F} 1)$. These are all aft dominated, with well-defined lobe pattern in the aft. Interestingly, the relative strengths of these interactions are relatively close in amplitude, since the amplitudes of $\mathrm{C} 1>\mathrm{C} 2$ but the amplitudes of F2 > F1. 


\section{SYMMETRY COMPARISIONS}

The 10' radius circular arrays (constant radius from the inlet or bypass plane), and the 88" linear array (constant distance from the engine center line) were moved to the right-hand-side (RHS) of the DART, and data acquired in a manner similar to that of the left-hand side (LHS). Potentially, the DART will be tested in the GRC 9x15 LWST the test section and acoustic traverse measurement would be on the right-hand-side of the engine. Therefore, it was desirable to determine if the pylon-side (RHS) acoustic directivity was significantly affected by the pylon. The acoustic directivity for the comparisons of the array configurations will be presented as total, broadband, and tonal components. All sets of data are at $92.5 \%$ corrected fan rpm and the OASPL is integrated over the $100 \mathrm{~Hz}$ to $40 \mathrm{kHz}$ frequency range.

Figure 21 presents a comparison of the acoustic directivity as measured by the circular, constant radius microphone array at 92.5\% RPMc-Fan. There are slight differences in the SPL levels, such that in general the RHS is attenuated - presumably due to the blockage of the pylon. This is noted across all 3 spectral components.

Figure 22 presents a comparison of the acoustic directivity as measured by the linear, constant distance microphone array. For ease of comparison, the levels are as measured (not adjusted for the different distance), as the intent is to compare symmetry. Projections to common distances are presented in reference [5]. At the angle with the peak SPL in the aft, the levels are lower on the RHS, conversely, as the aft angle increases the RHS levels are slightly higher. As the array extends forward, the levels approach near symmetry. This indicates that the effect of the pylon is to provide some shielding with possible refraction toward the higher aft angles. The influence of the pylon is minimally felt in the forward arc.

The differences between the RHS and LHS arrays are shown on Figure 23. (+delta indicates the RHS is increased in level; - indicates the RHS is quieter, compared to the LHS). A first approximation is that these differences do not preclude acquiring meaningful acoustic data from the pylon side of the engine. 


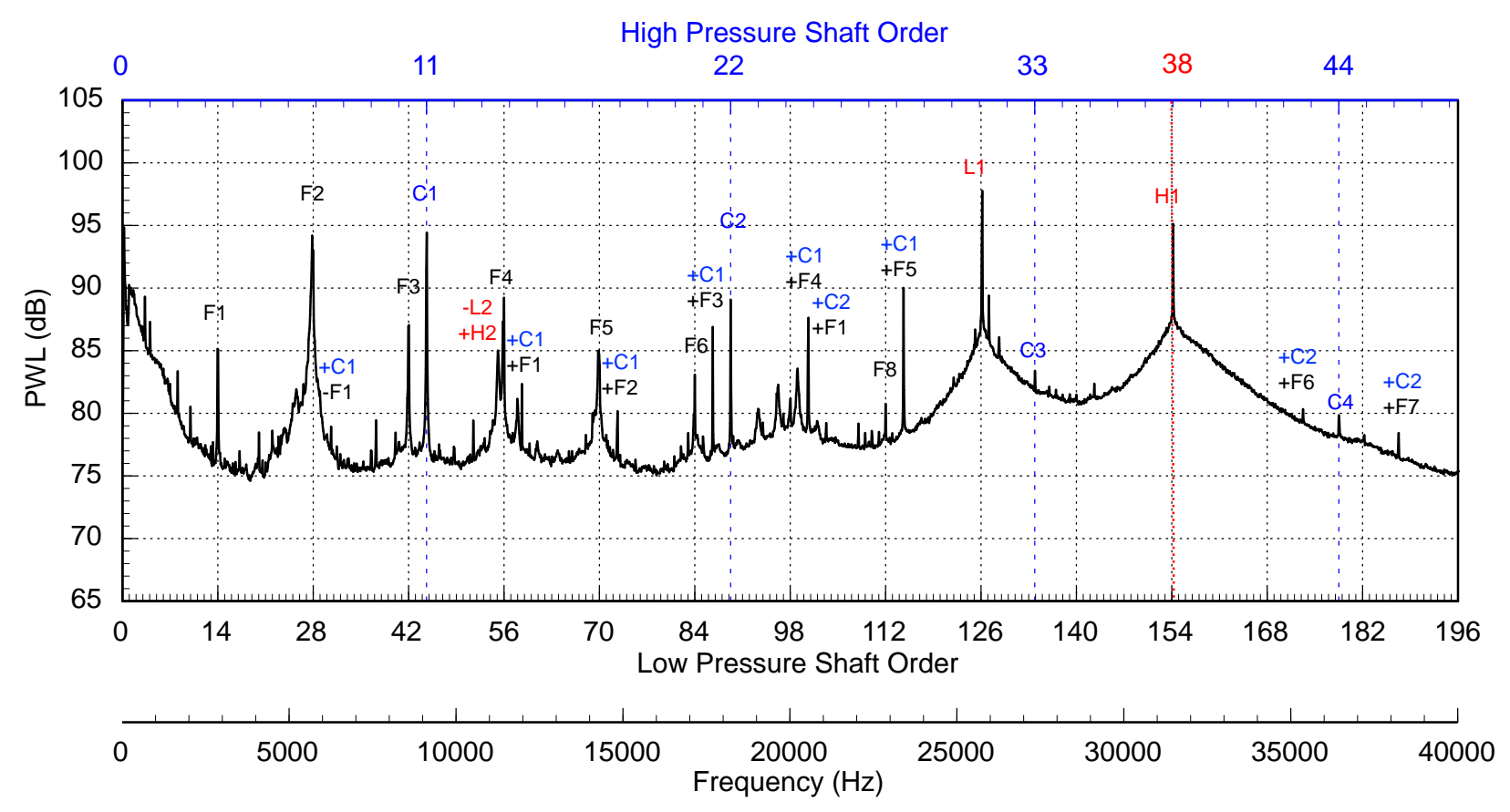

(a) Aft Mic Array Summation @ 92.5\% RPMc-Fan

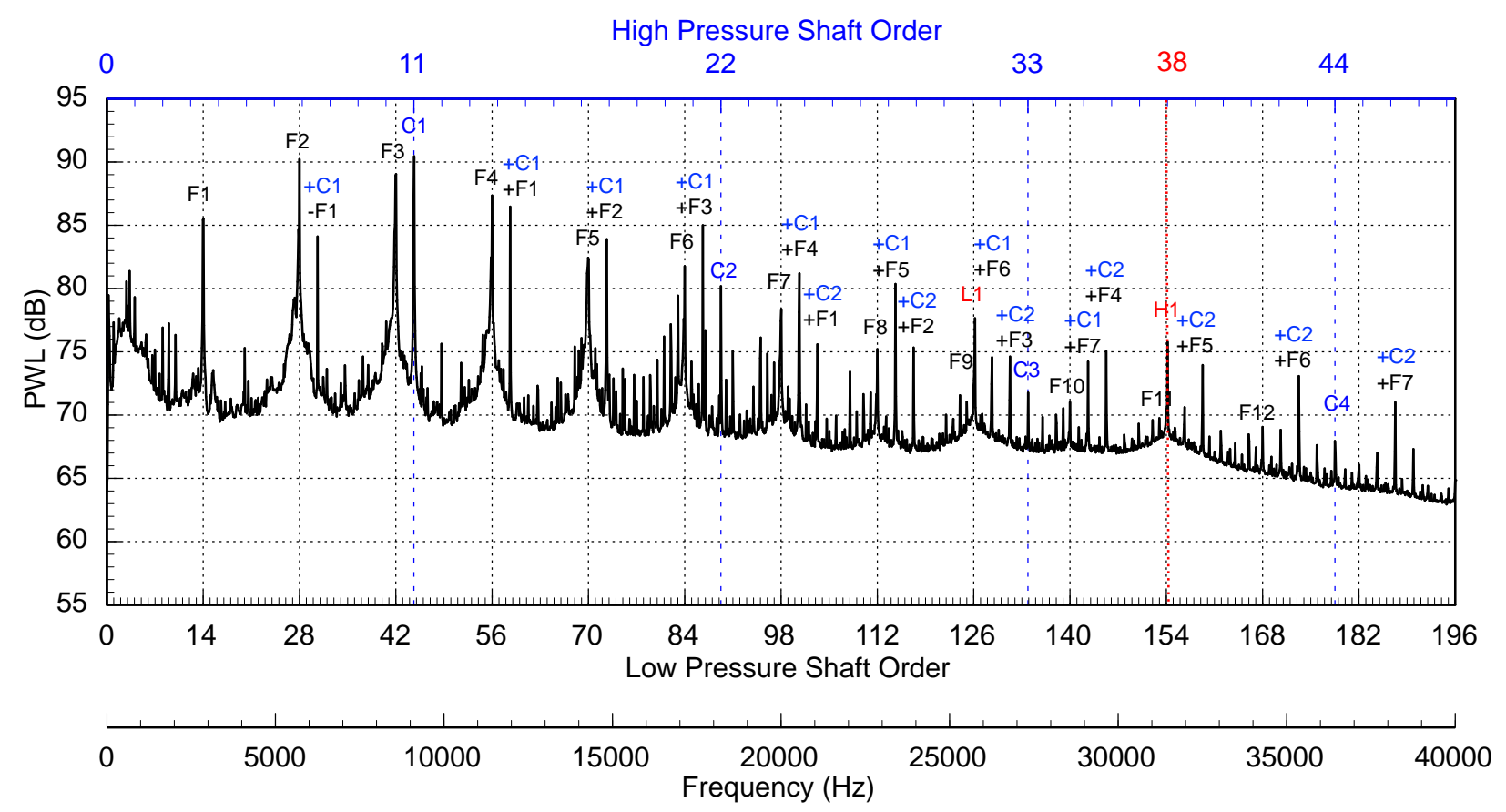

(b) Forward Mic Array Summation @ 92.5\% RPMc-Fan

Figure 8. Average of Spectra for each Arc Showing Harmonics and Interactions.

13

American Institute of Aeronautics and Astronautics 

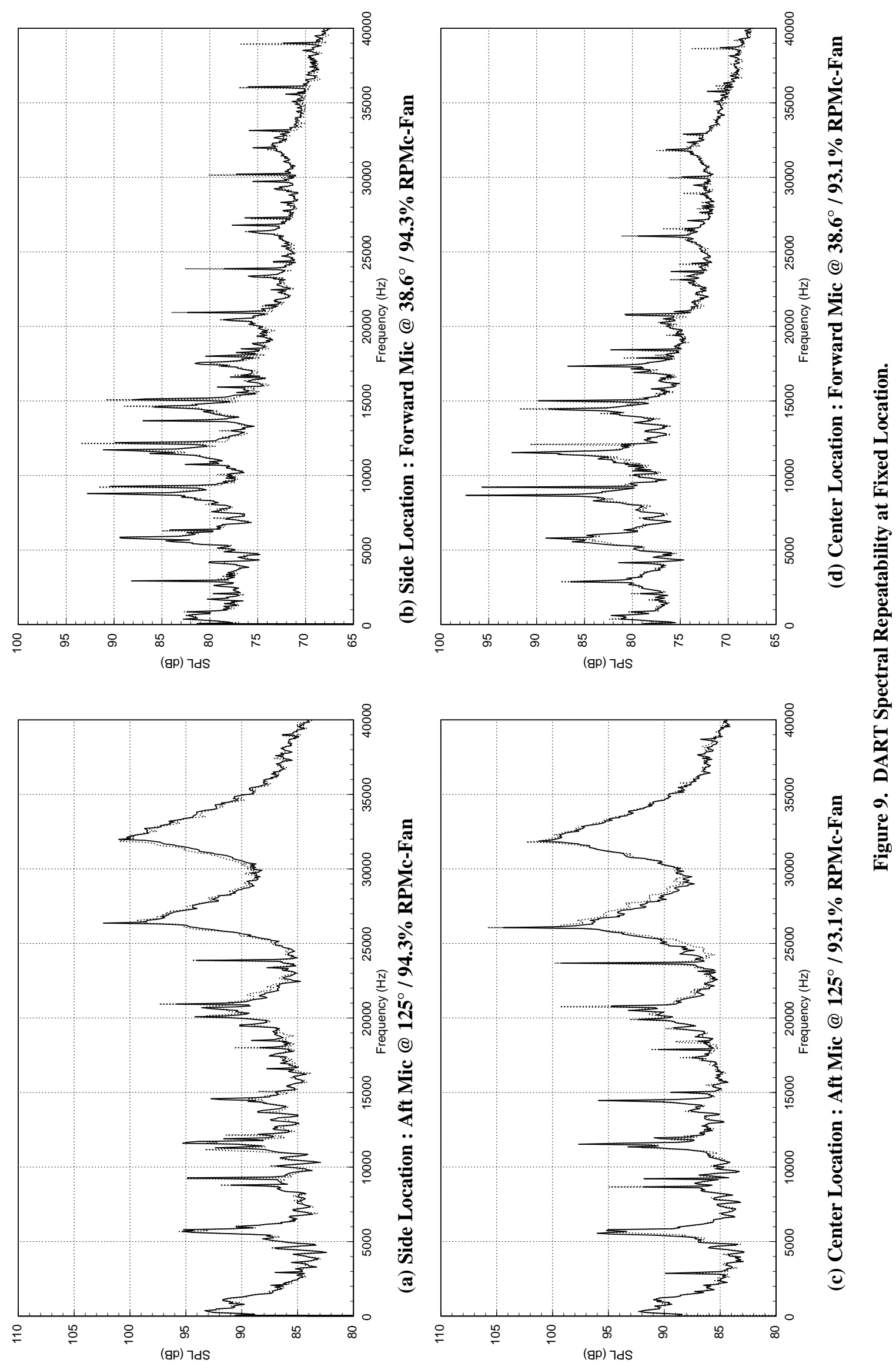


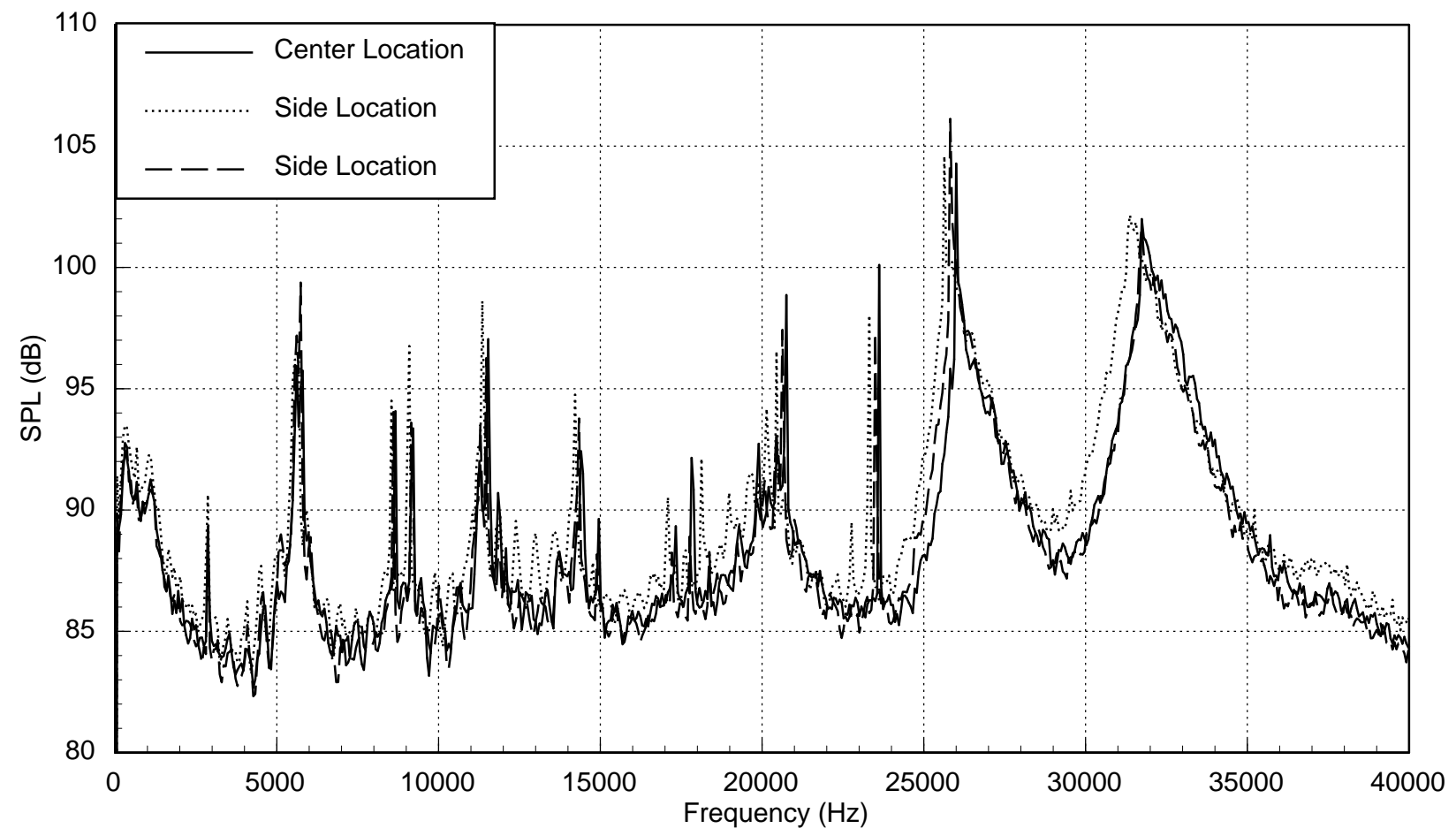

(a) Aft Mic @ 125.0 / 92.5\% RPMc-Fan

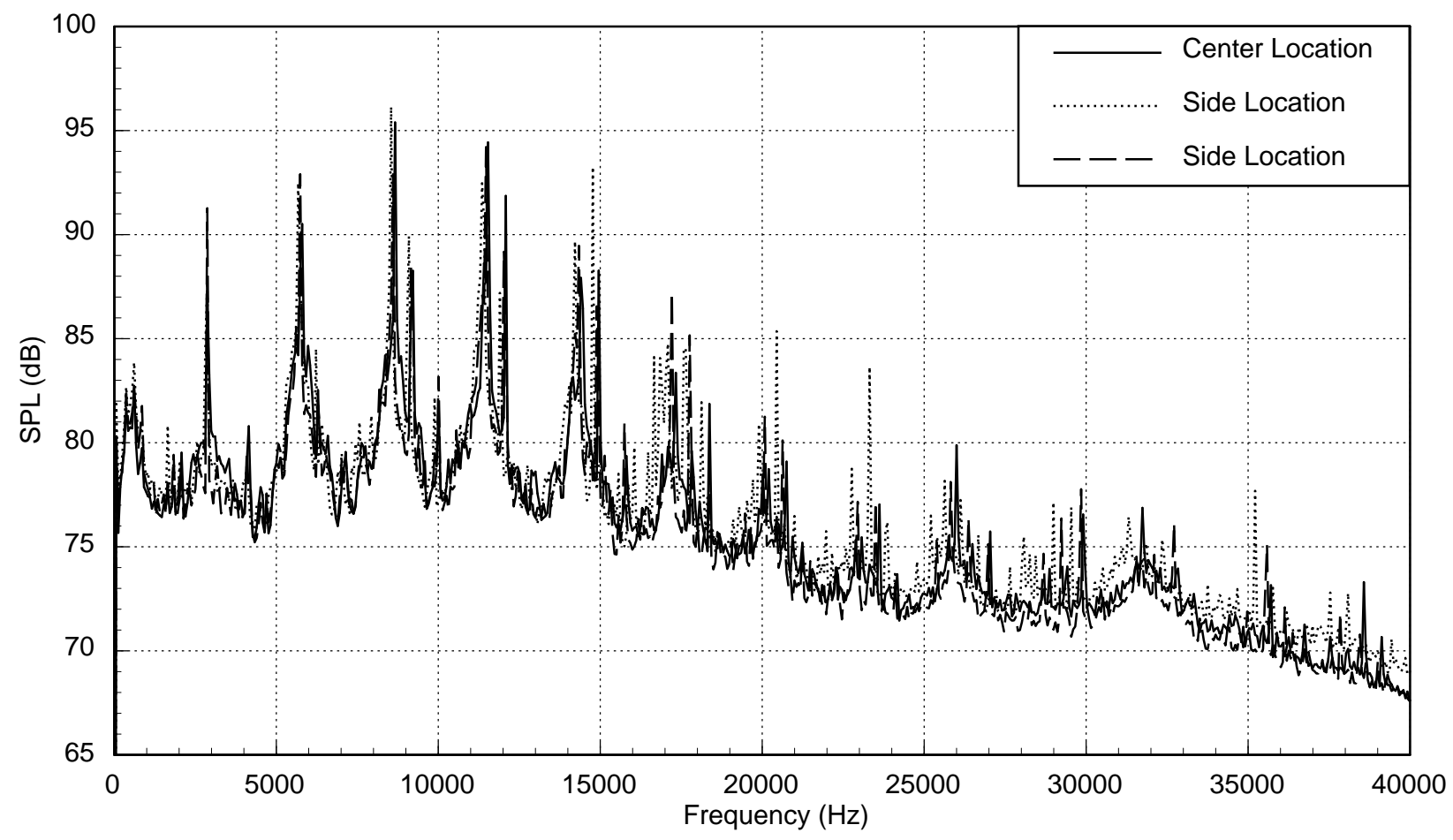

(b) Forward Mic @ 38.6 $/ 92.5 \%$ RPMc-Fan

Figure 10. DART Spectral Repeatability between Locations. 


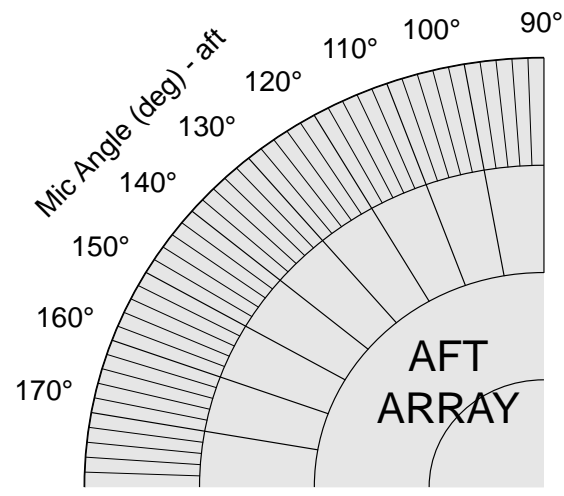

SPL (dB)

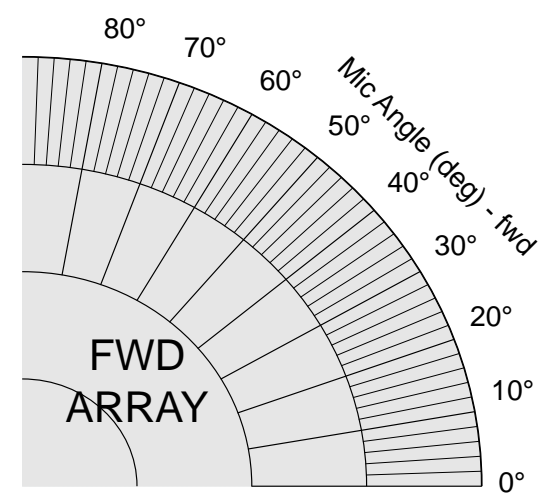

SPL (dB)

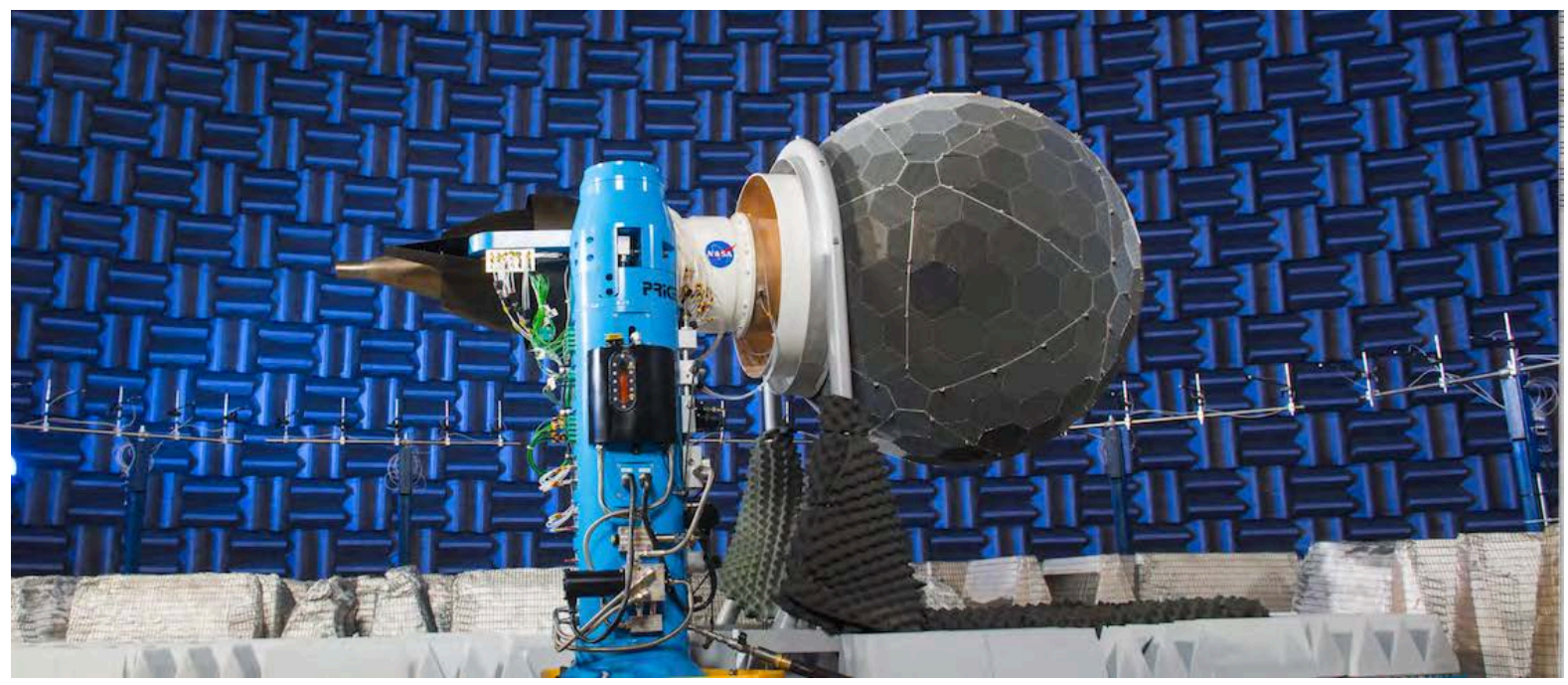

Figure 11. Clarification of Polar-Plot Orientation.

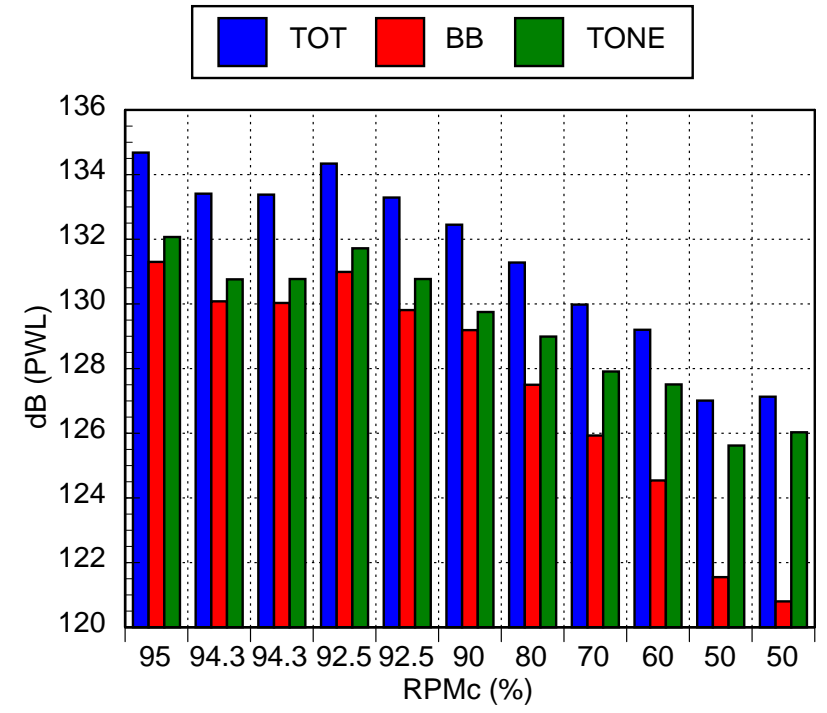

(a) AFT arc

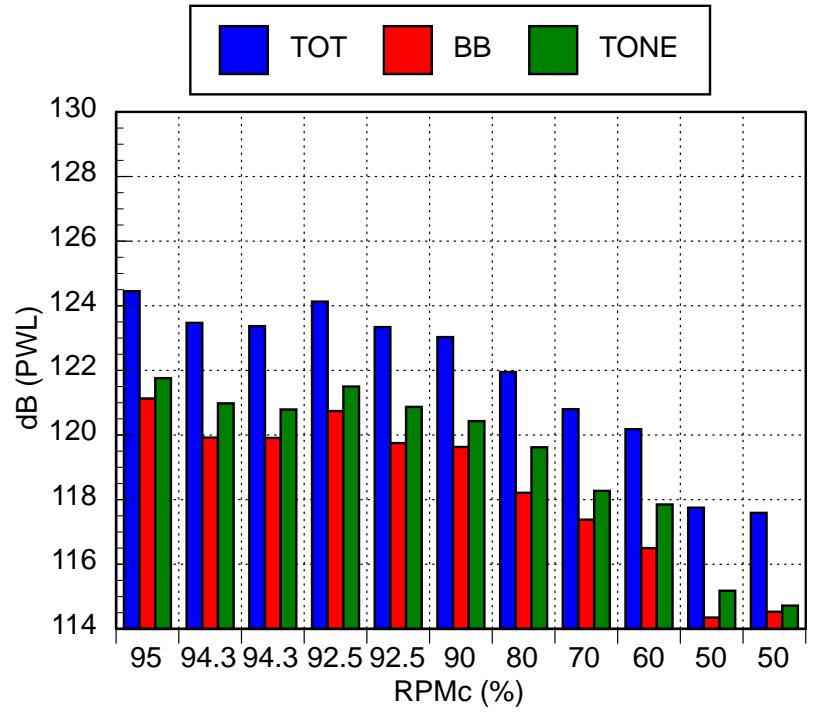

(b) FWD arc

Figure 12. DART PWL vs. RPMc-Fan. 


\section{- Set-Point 10 …… Set-Point 8}
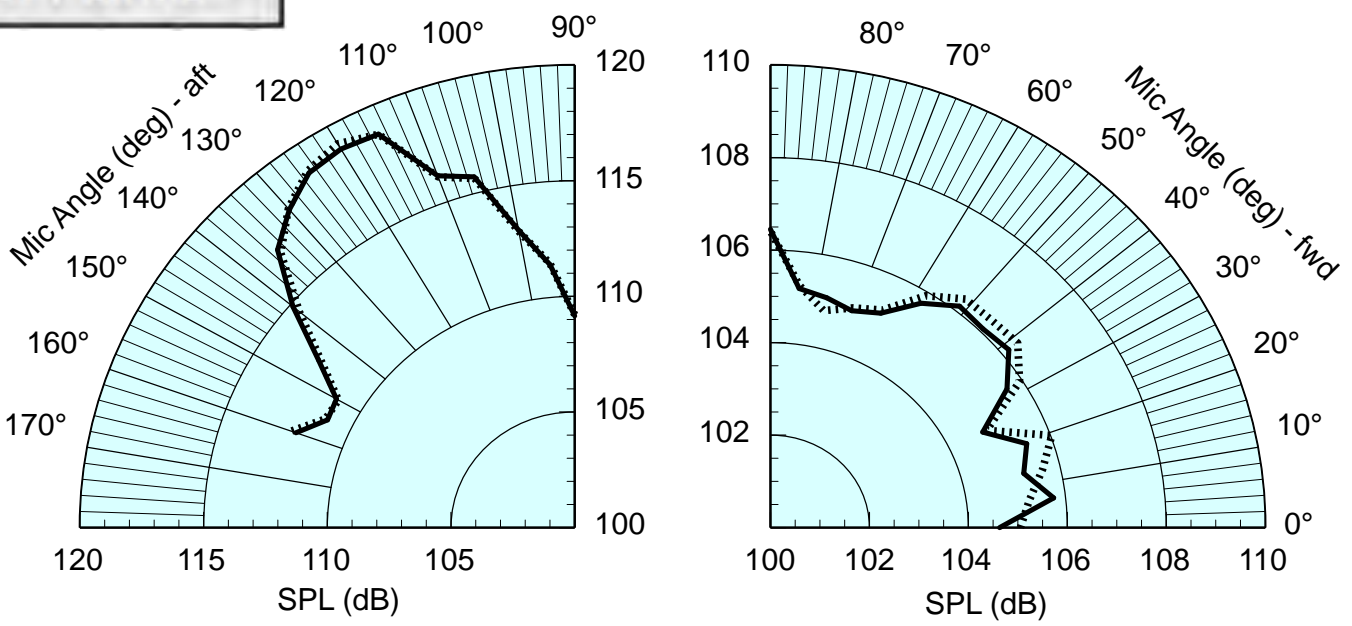

(a) Total Integrated SPL
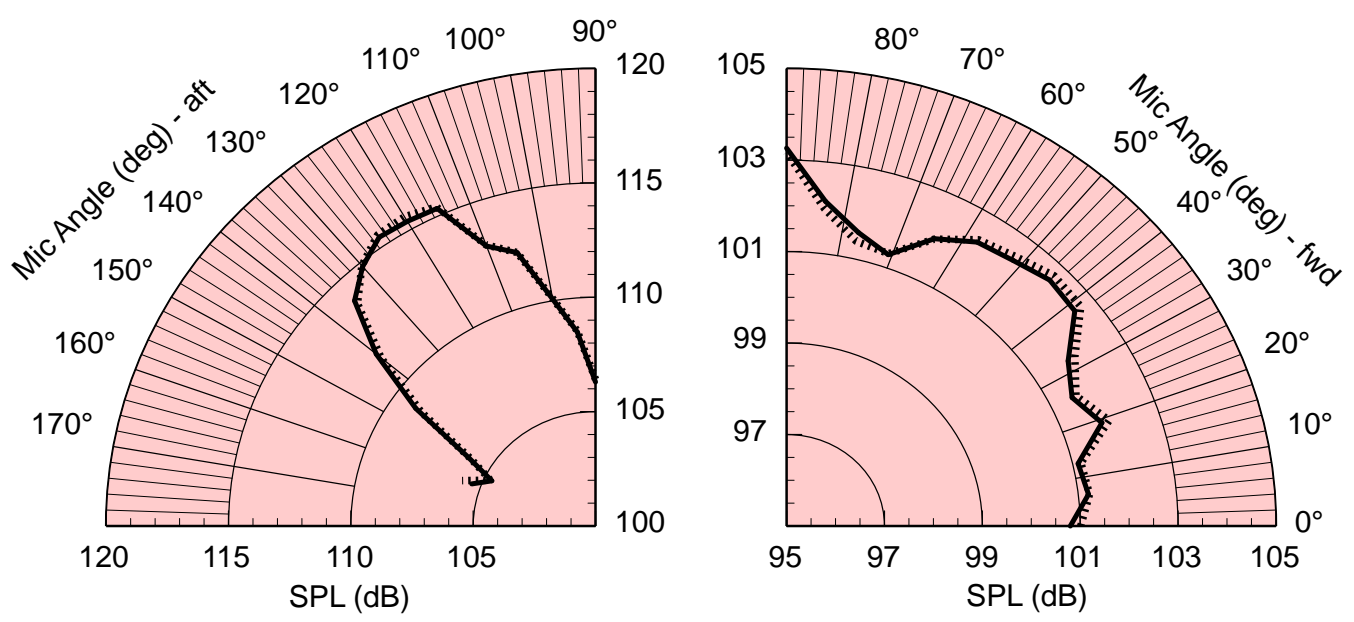

(b) Broadband Integrated SPL
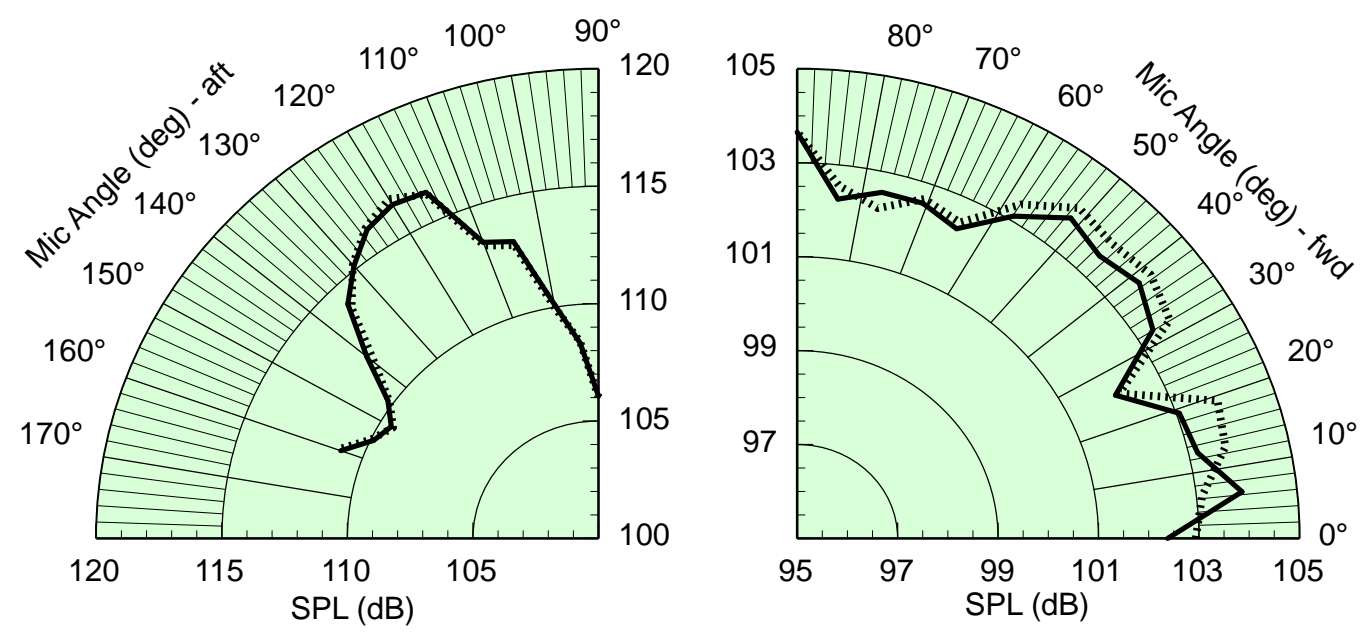

(c) Tonal Integrated SPL

Figure 13. Acoustic Directivity with DART at Side Location: 94.3\% RPMc-Fan 


\section{- Set-Point 10 in!.. Set-Point 8}
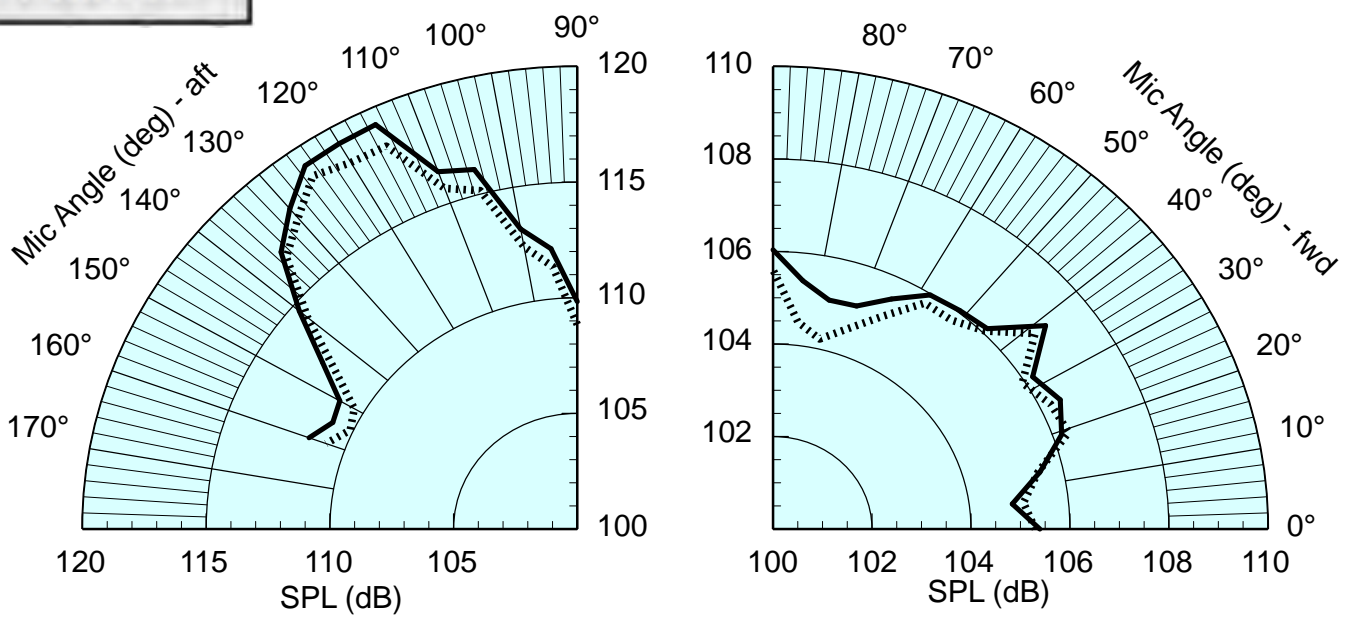

(a) Total Integrated SPL
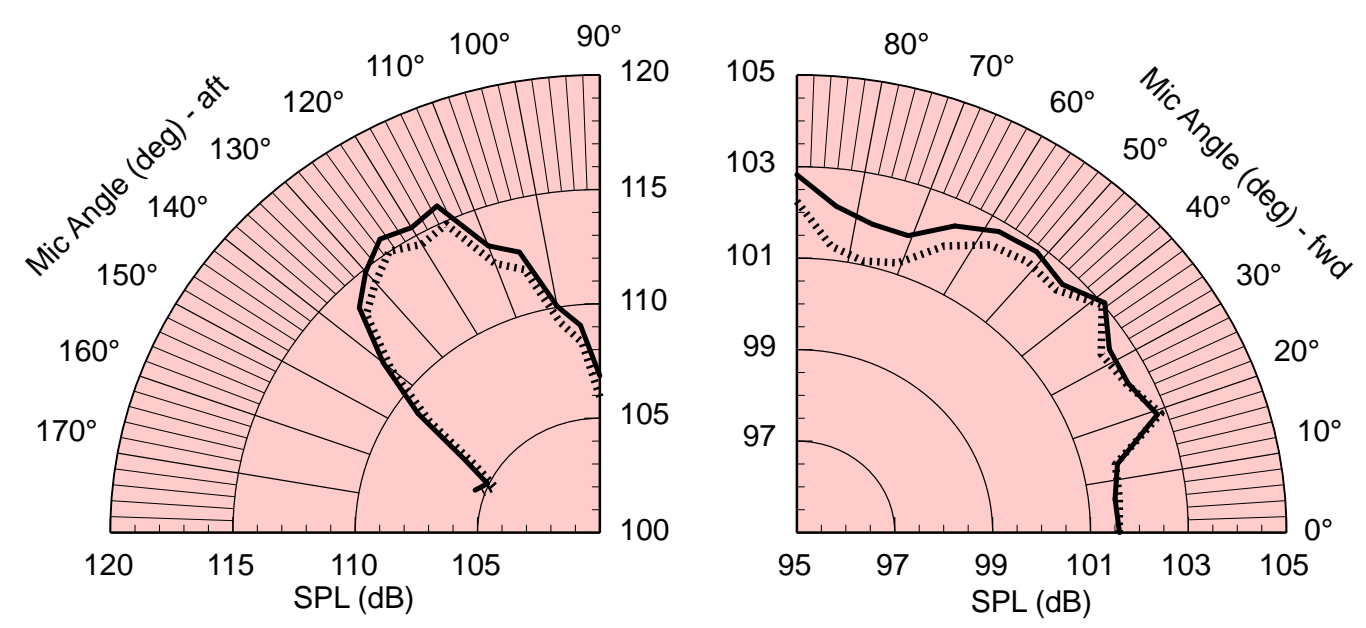

(b) Broadband Integrated SPL
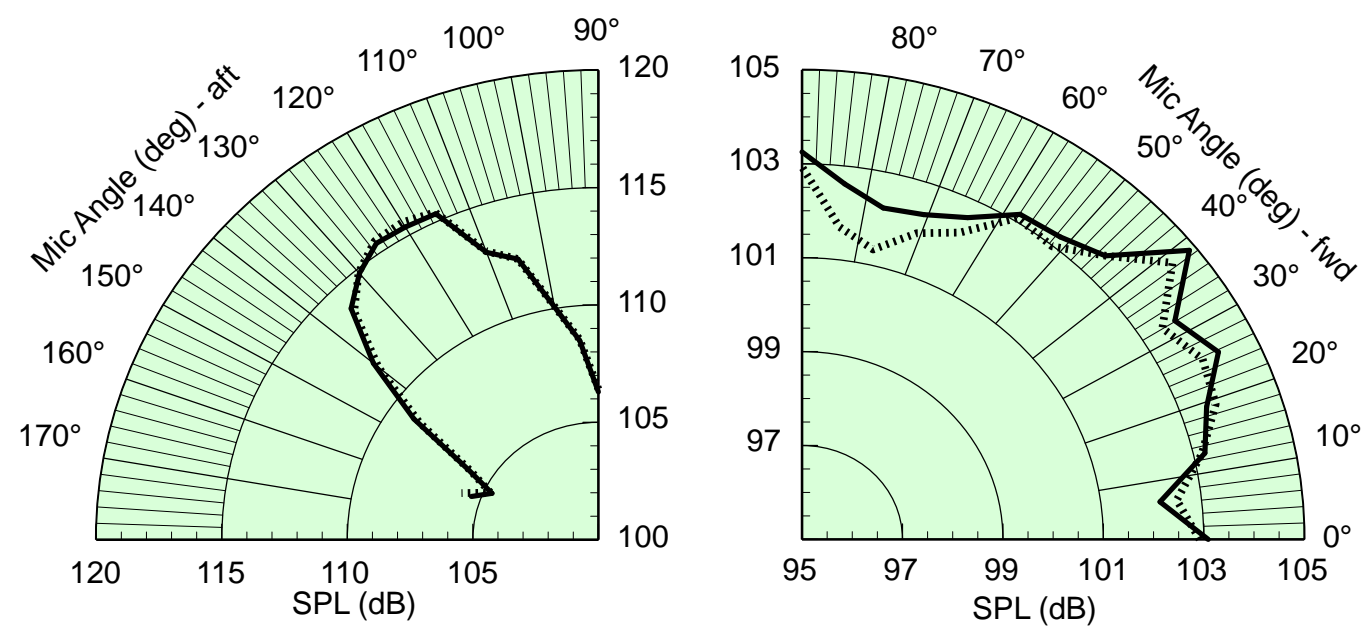

(c) Tonal Integrated SPL

Figure 14. Acoustic Directivity with DART at Center Location: 93.1\% RPMc-Fan 

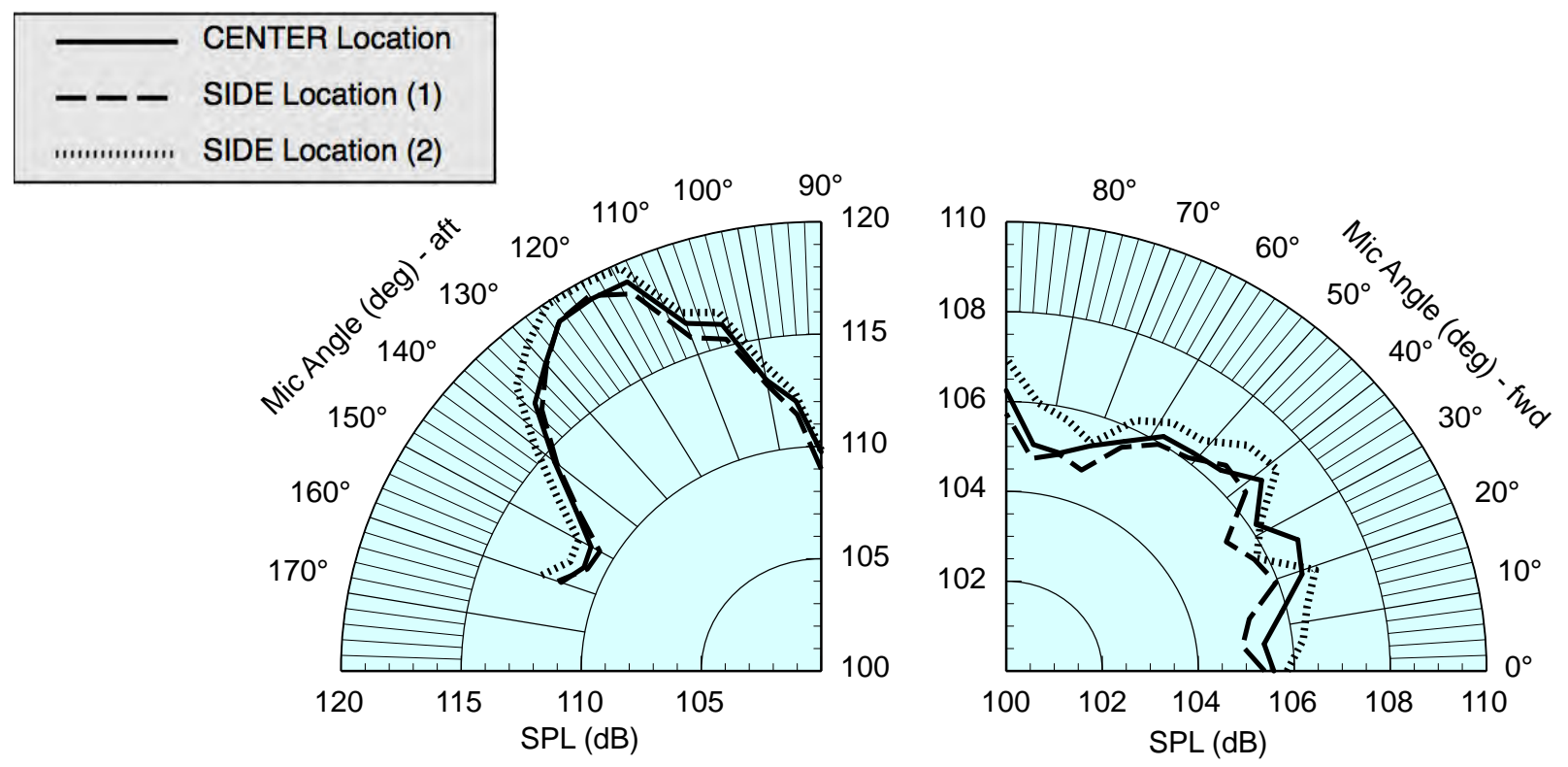

(a) Total Integrated SPL
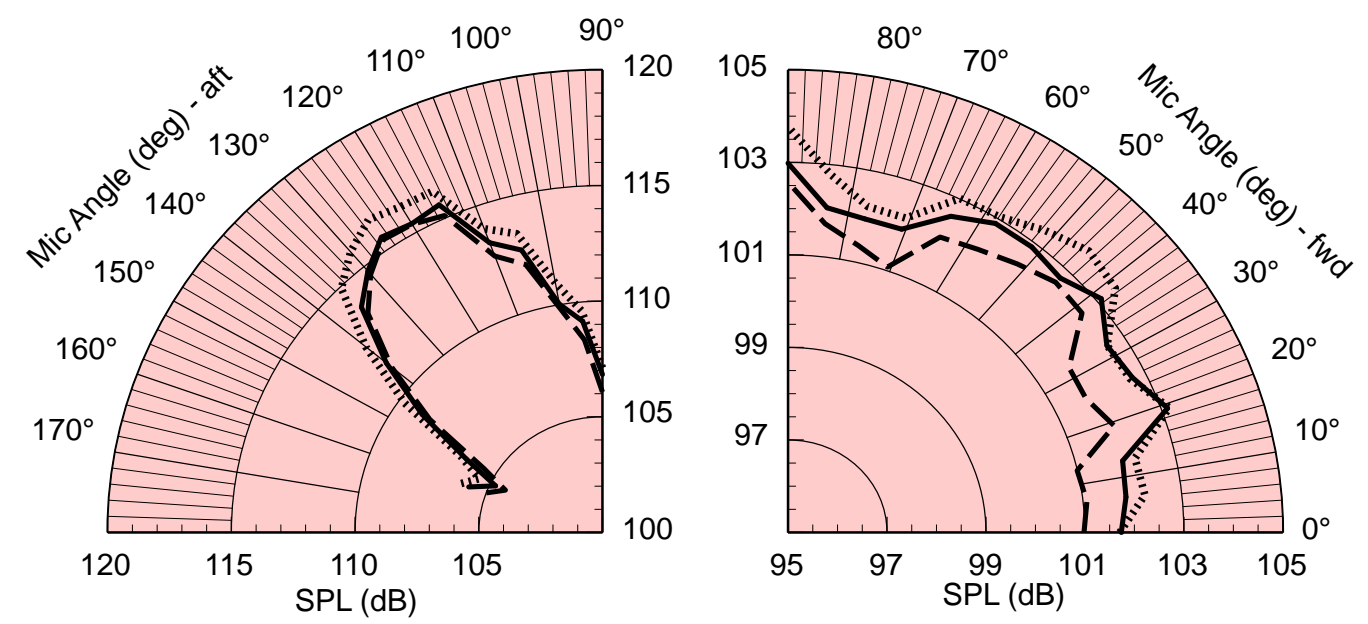

(b) Broadband Integrated SPL
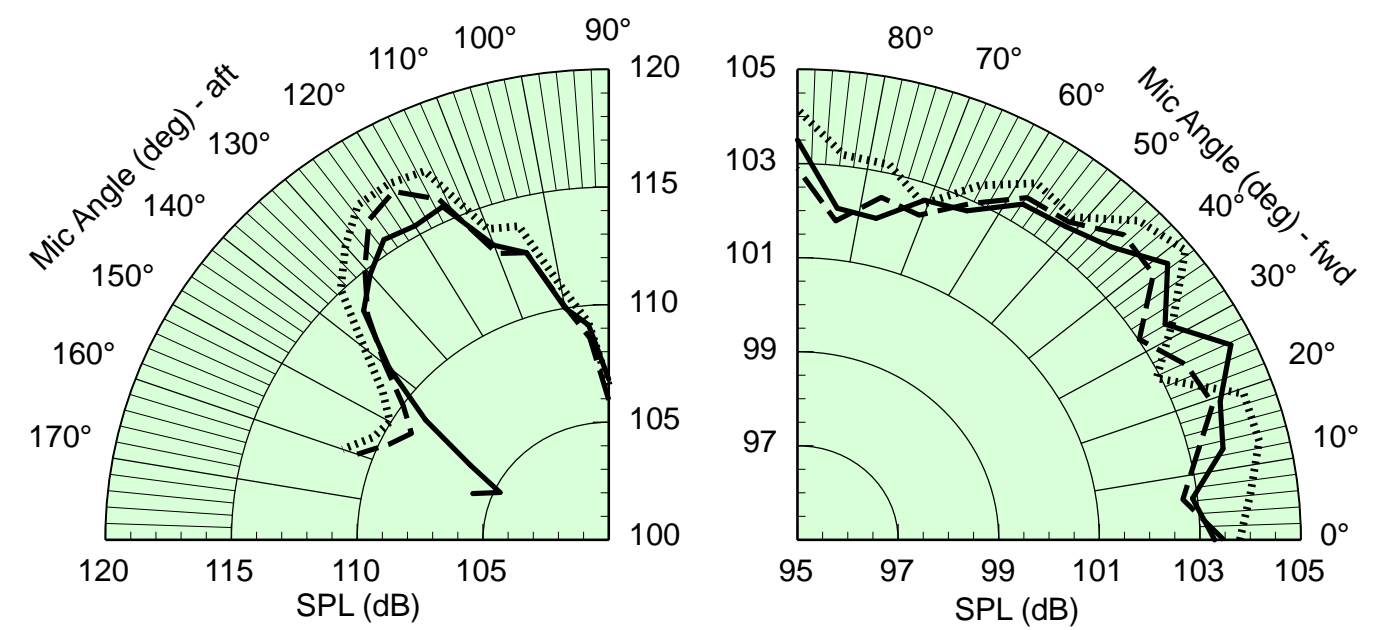

(c) Tonal Integrated SPL

Figure 15. Acoustic Directivity Comparing DART Center vs Side Location: 92.5\% RPMc-Fan 

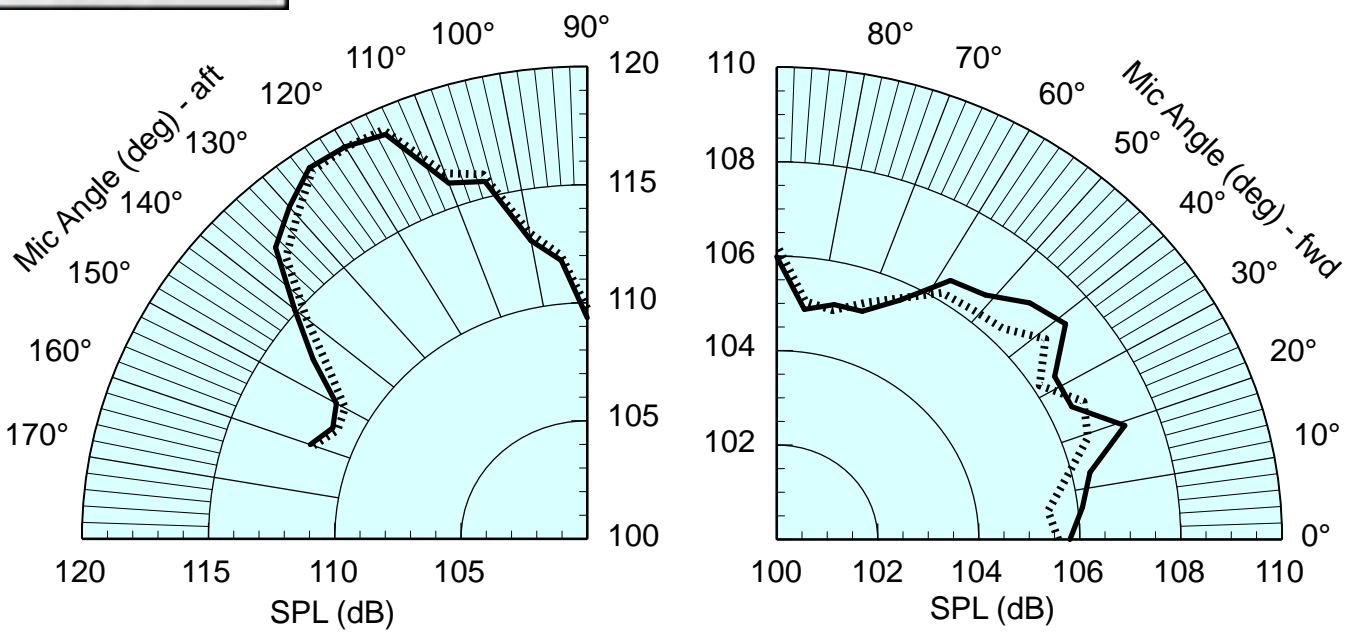

(a) Total Integrated SPL
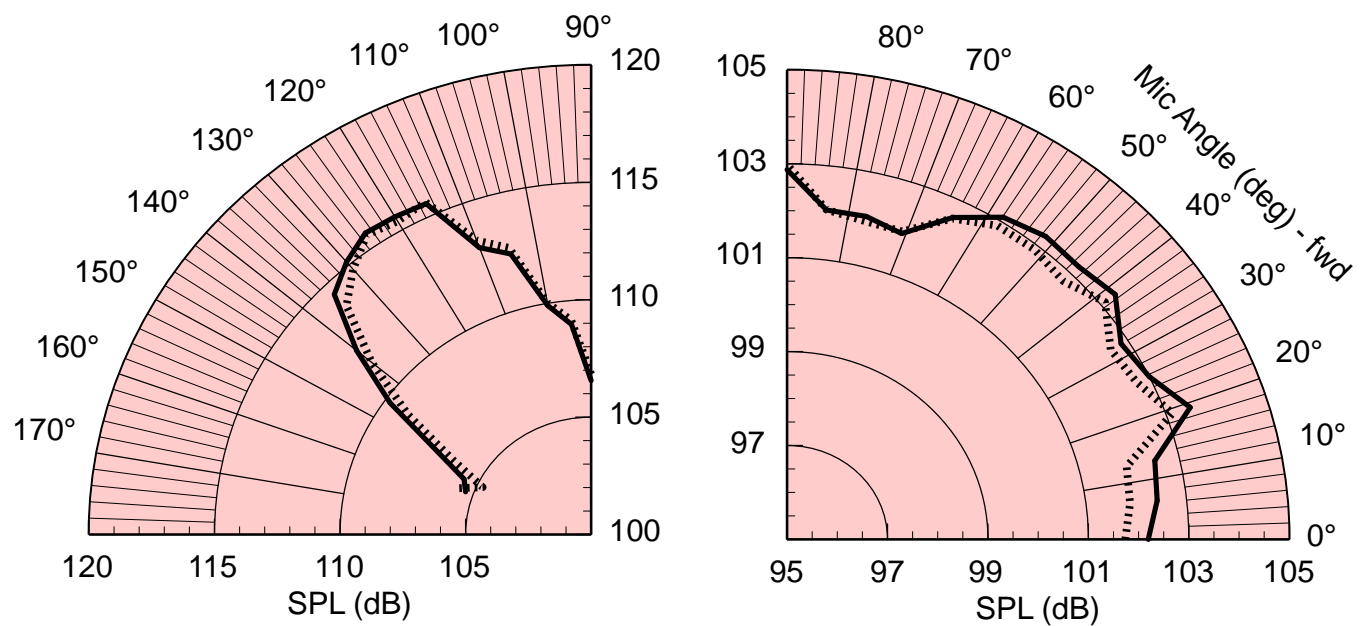

(b) Broadband Integrated SPL
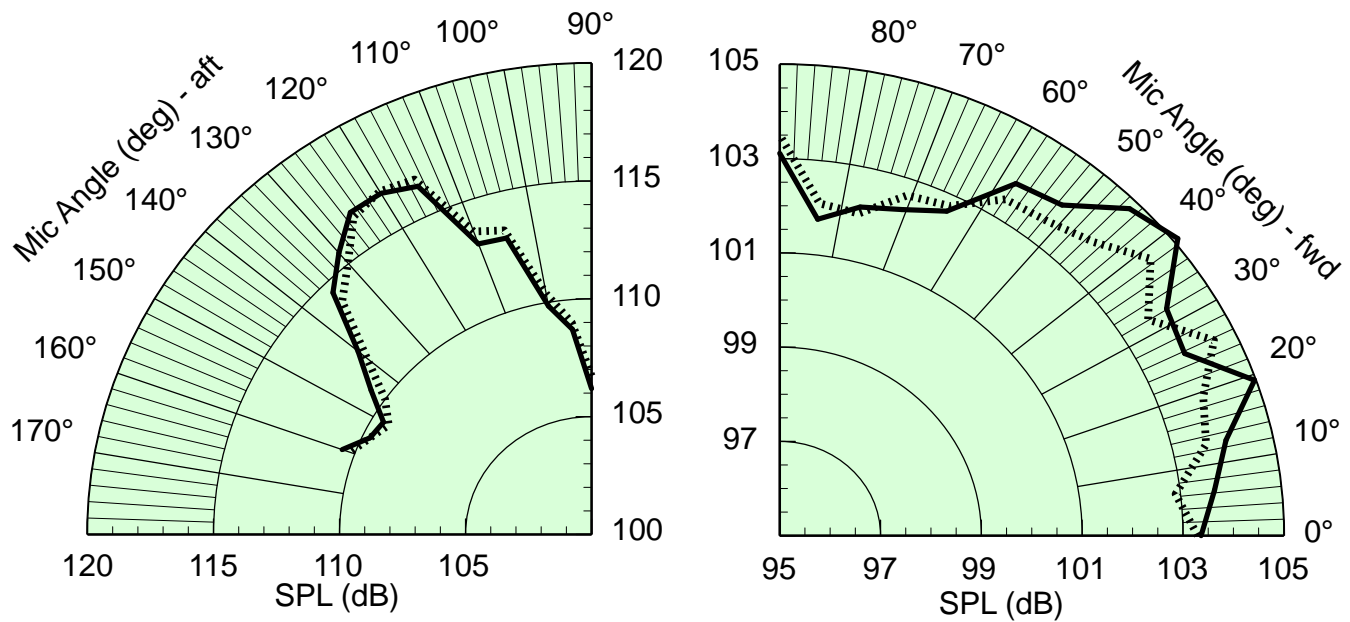

(c) Tonal Integrated SPL

Figure 16. Acoustic Directivity of DART Comparing Thrust Lockout : 92.5\% RPMc-Fan 
(a) F1
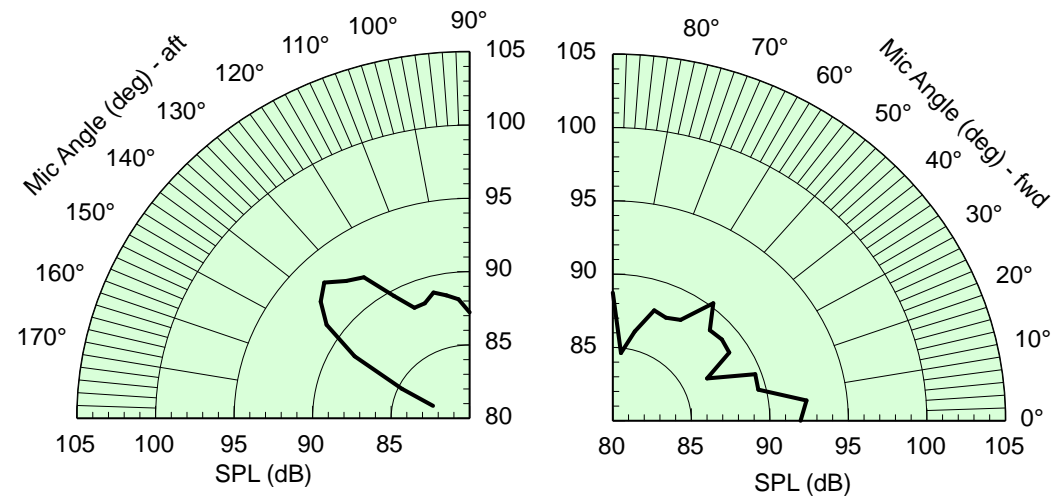

(b) F2
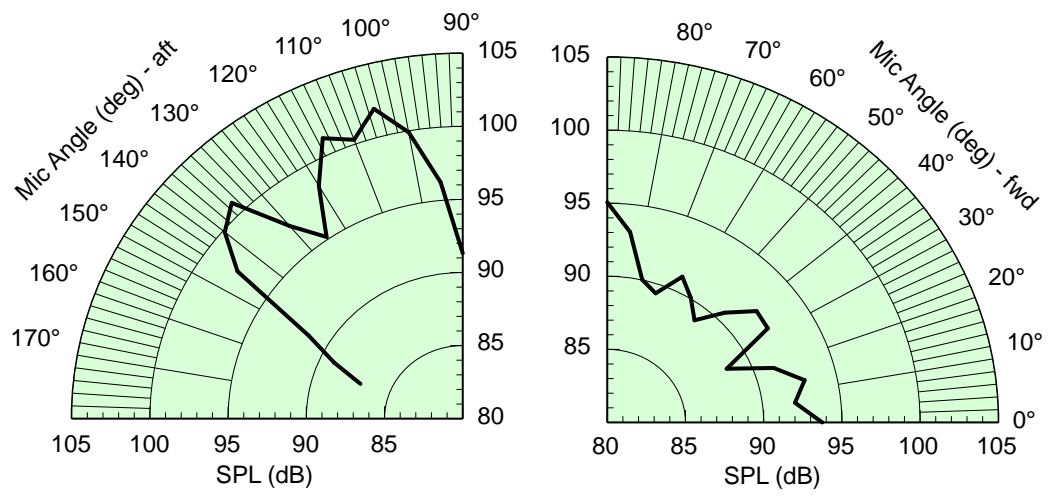

(c) F3
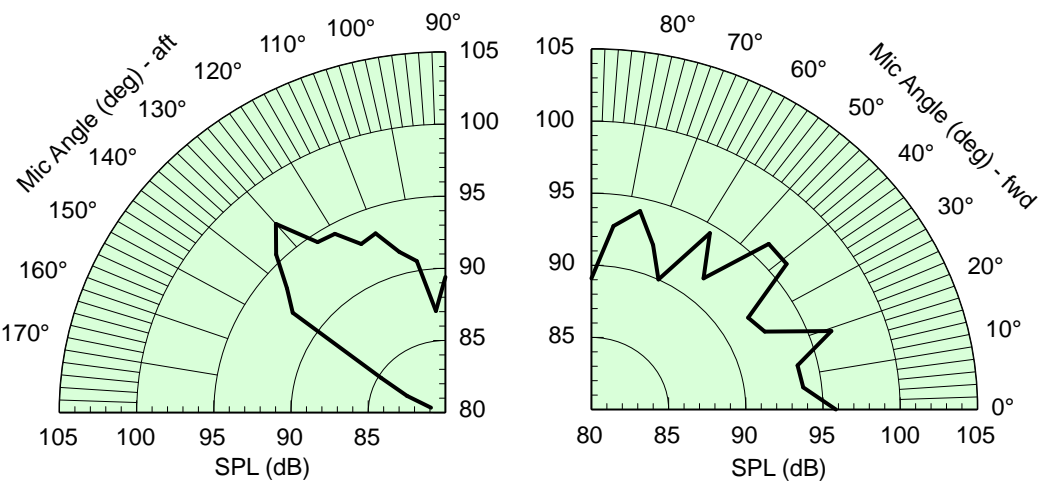

(d) F4
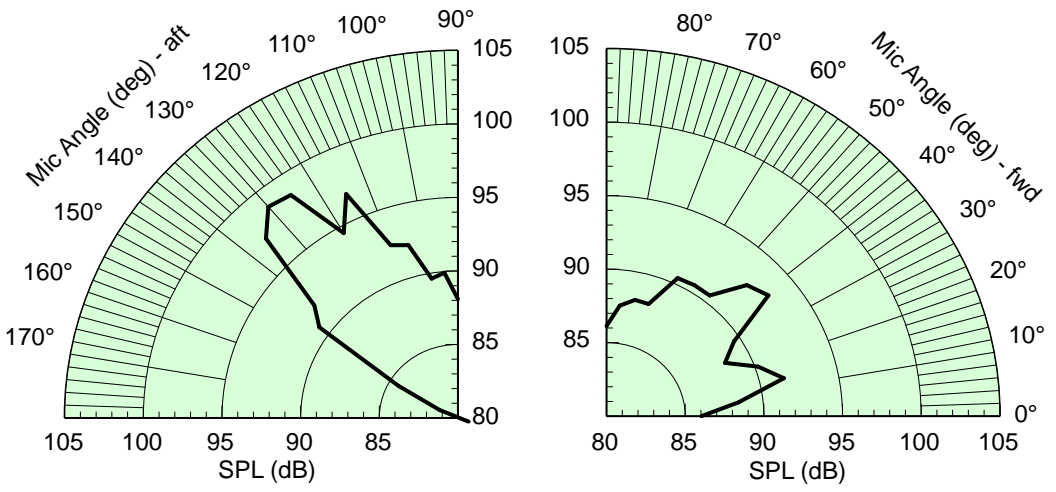

Figure 17. Acoustic Directivity of DART Fan Harmonics: 92.5\% RPMc-Fan 
(a) C1
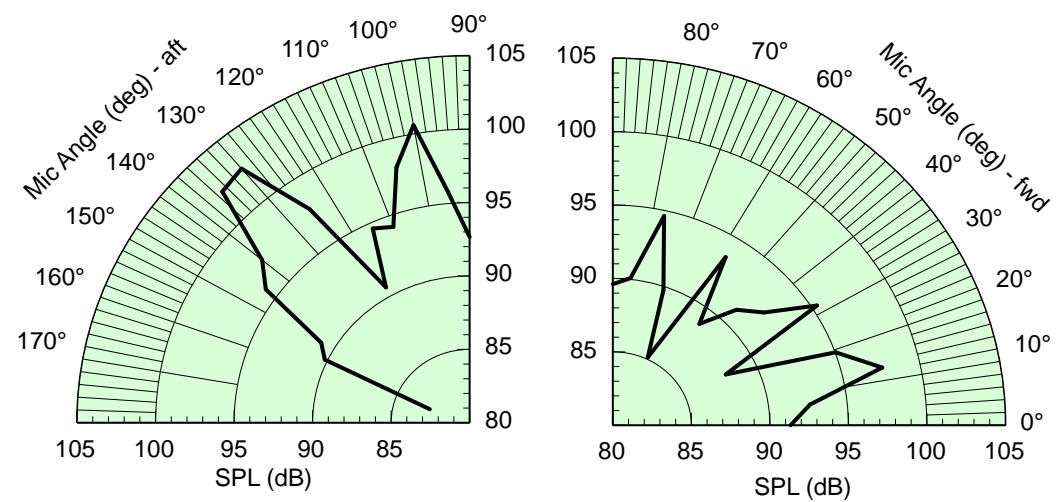

(b) $\mathrm{C} 2$
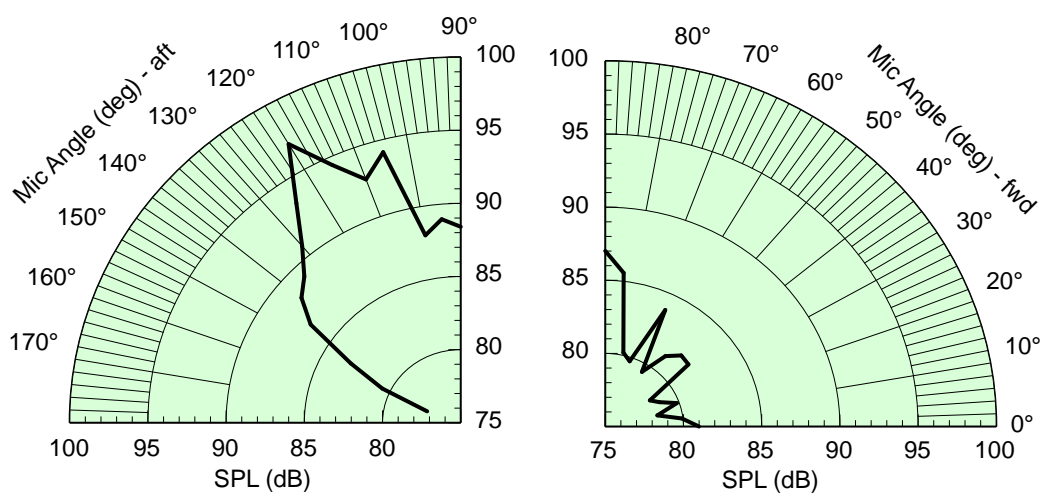

(c) $\mathrm{L} 1$
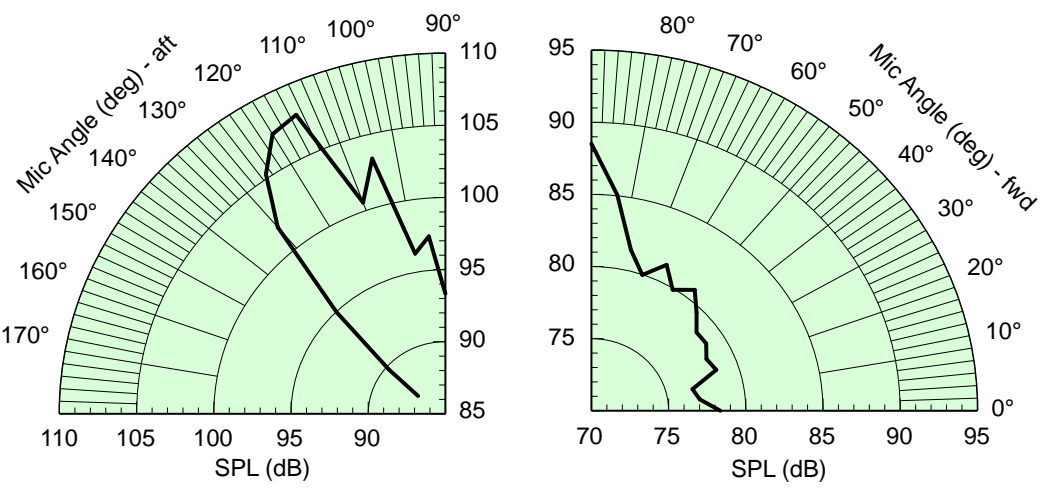

(d) $\mathrm{H1}$
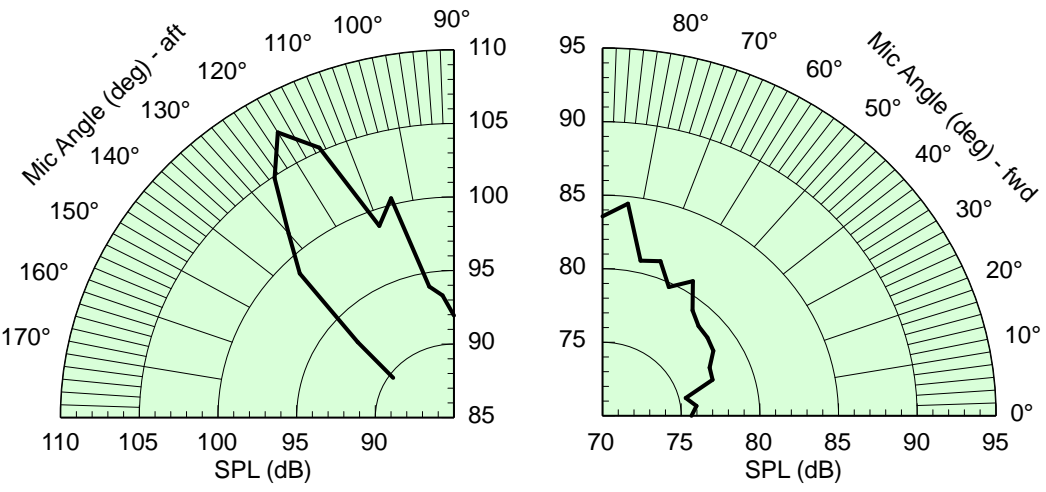

Figure 18. Acoustic Directivity of DART Compressor/Turbine Tones: 92.5\% RPMc-Fan 
(a) C1-F1
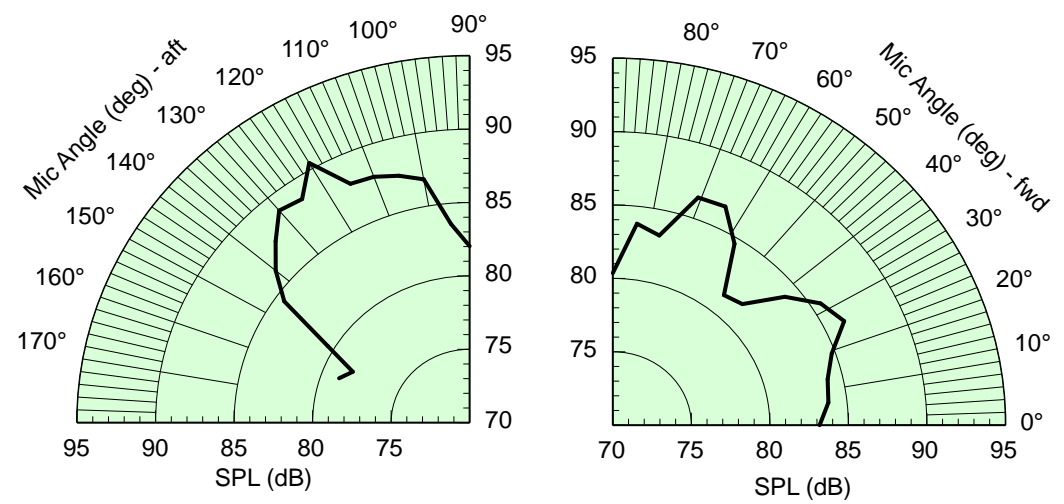

(b) $\mathrm{C} 1+\mathrm{F} 1$
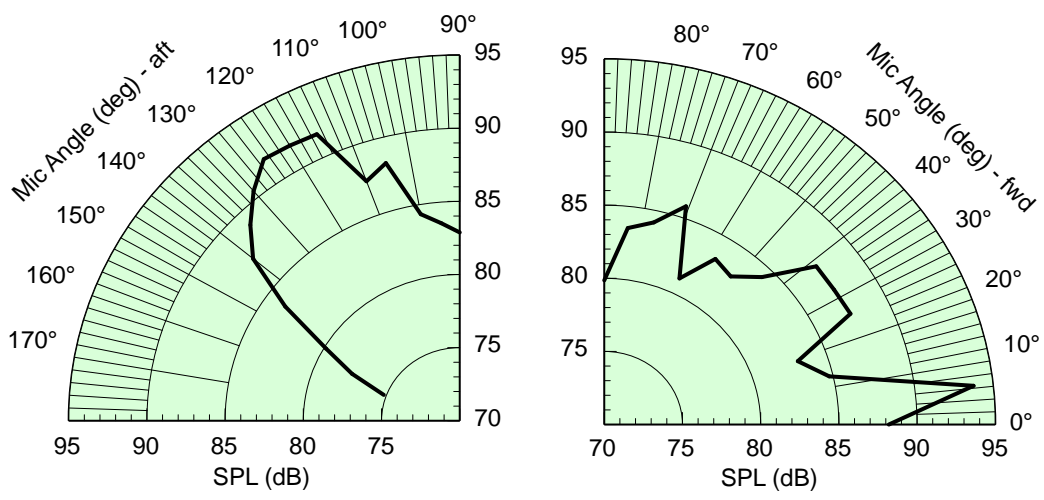

(c) C1-F2
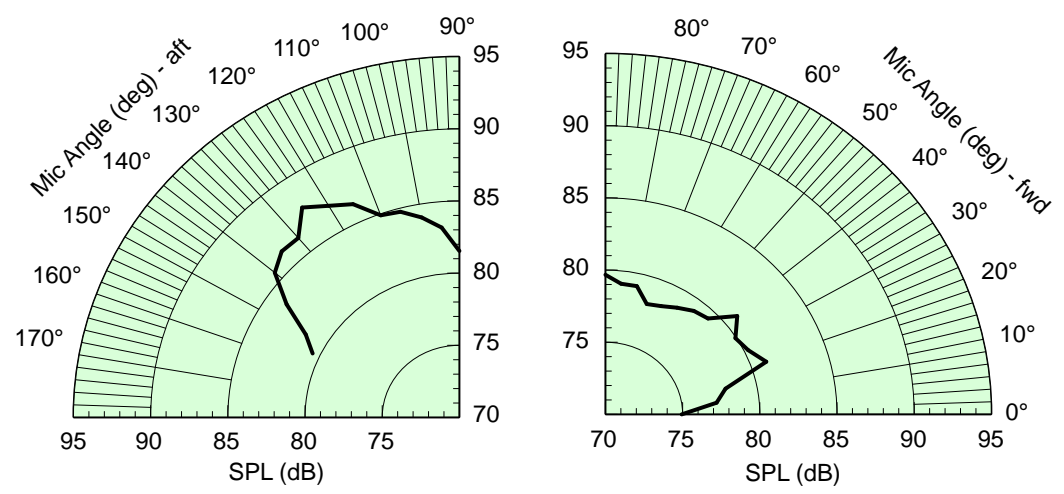

(d) $\mathrm{C} 1+\mathrm{F} 2$
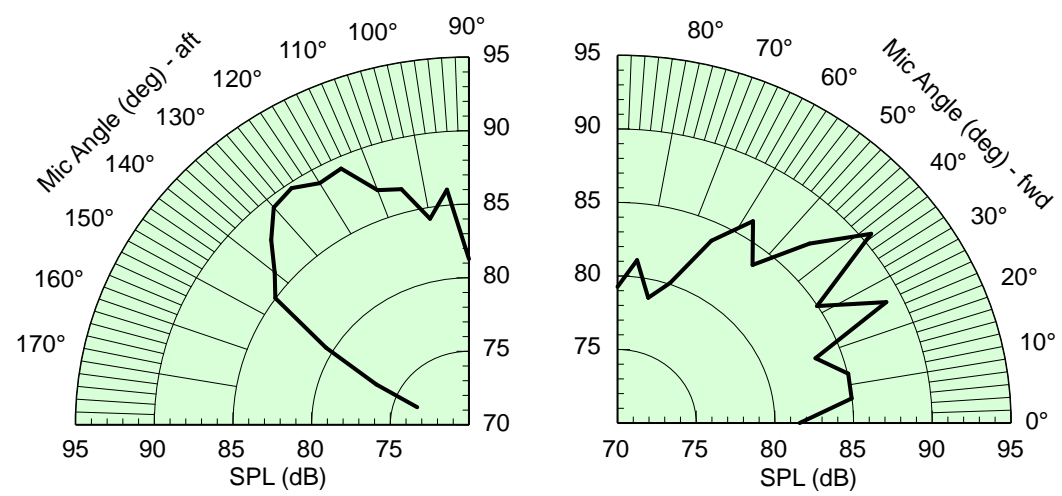

Figure 19. Acoustic Directivity of DART Compressor 1st Fundamental and Fan Fundamentals Interactions : 92.5\% RPMc-Fan 
(a) C2-F1
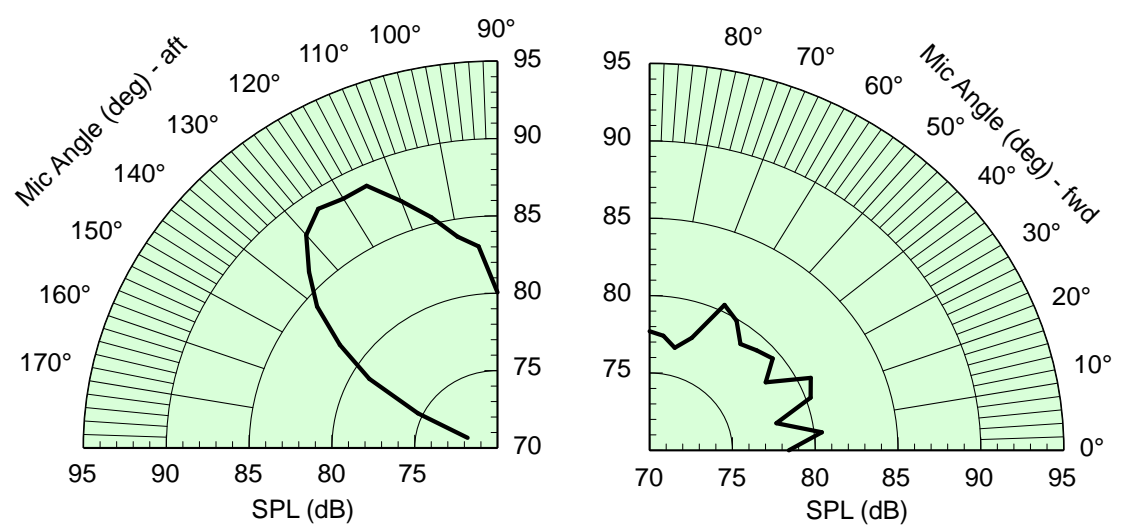

(b) $\mathrm{C} 2+\mathrm{F} 1$
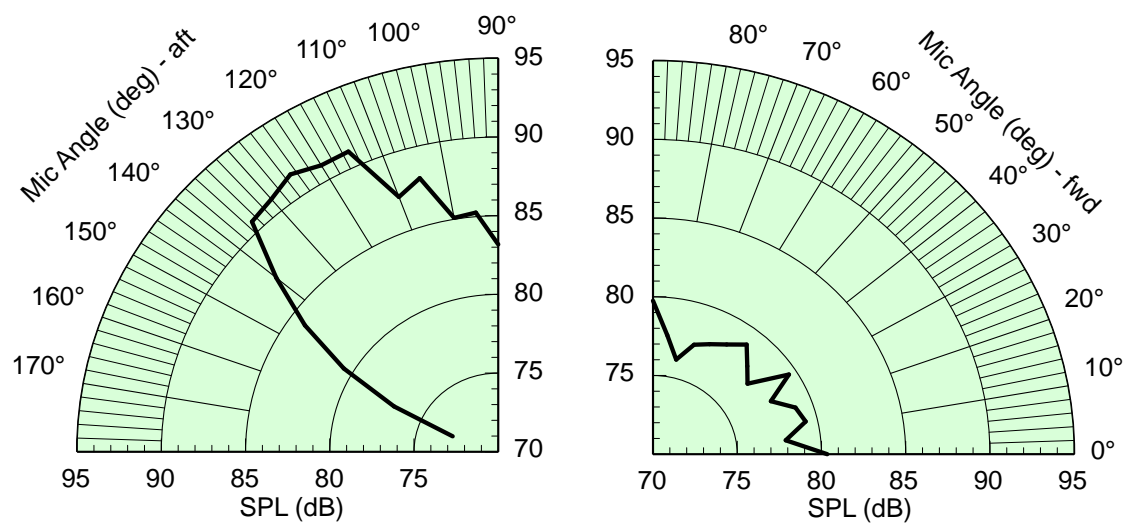

Figure 20. Acoustic Directivity of DART Compressor $2^{\text {nd }}$ Fundamental and Fan Fundamental Interactions: 92.5\% RPMc-Fan 

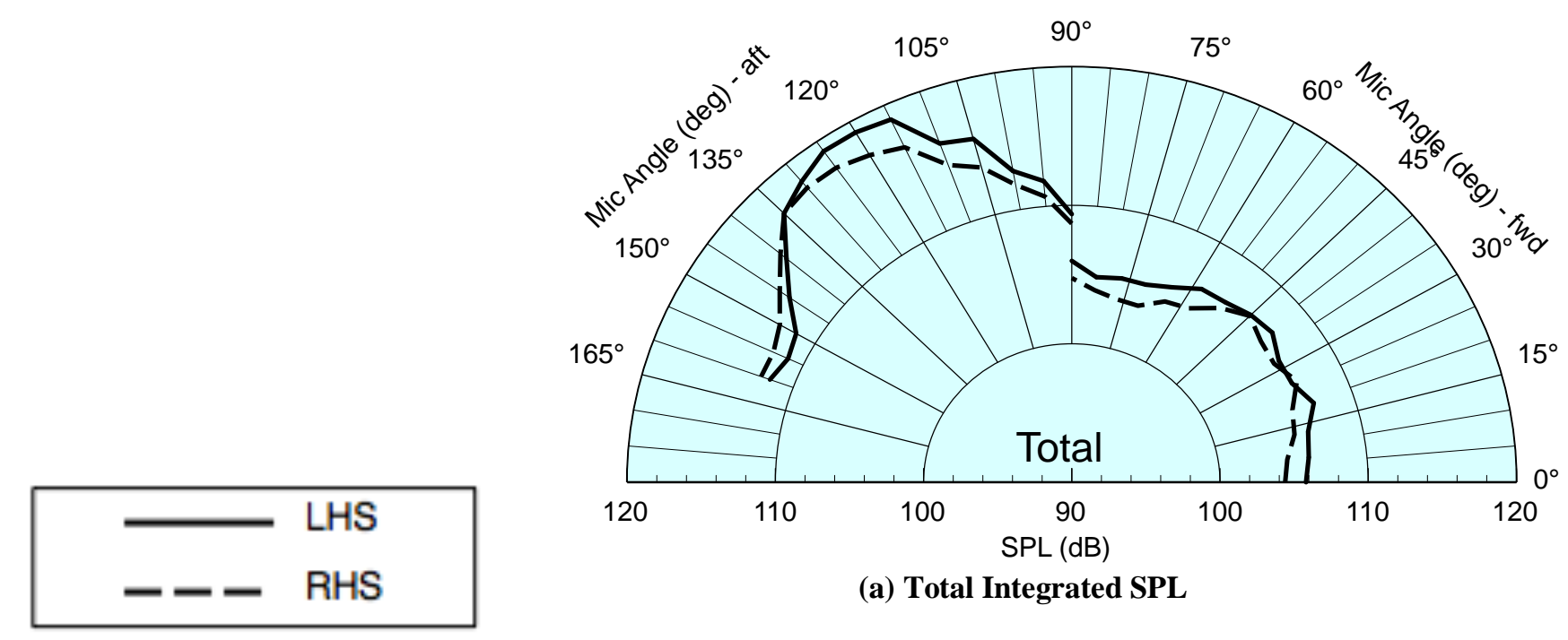

(a) Total Integrated SPL
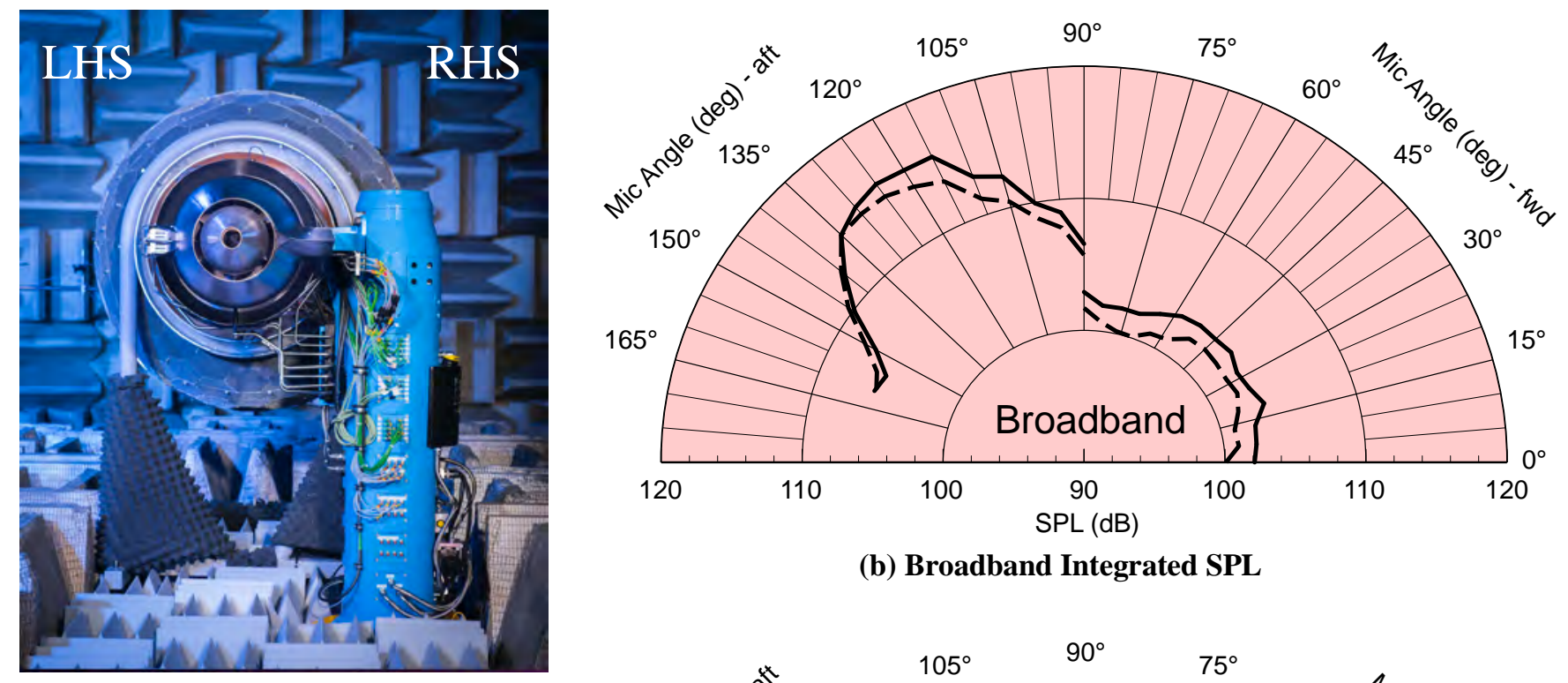

(b) Broadband Integrated SPL

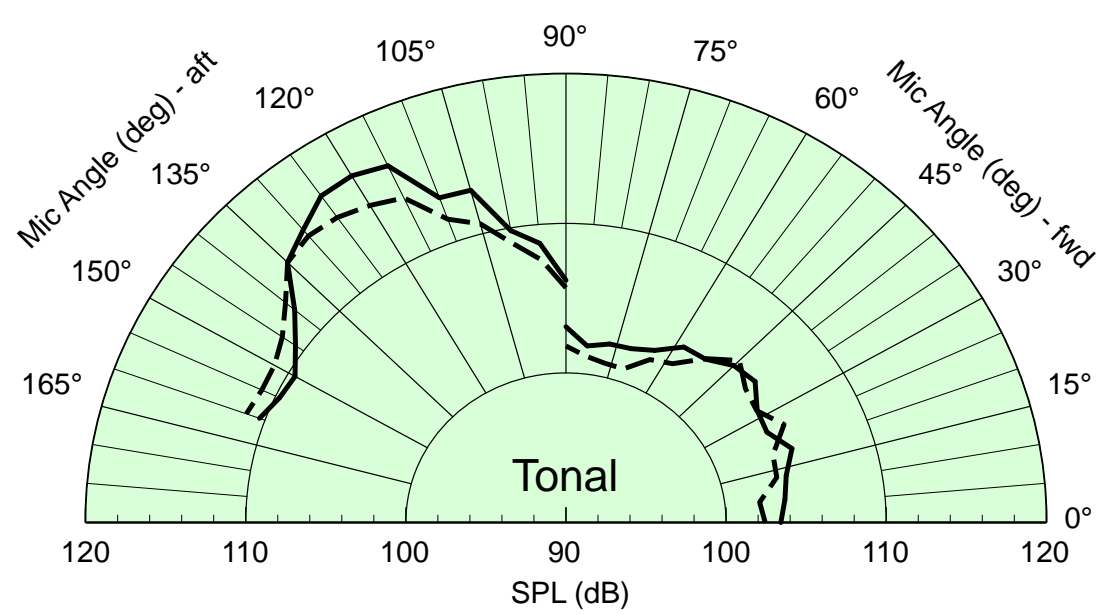

(c) Tonal Integrated SPL

Figure 21. Acoustic Directivity of DART LHS and RHS as Measured by Circular Array: 92.5\% RPMc-Fan 

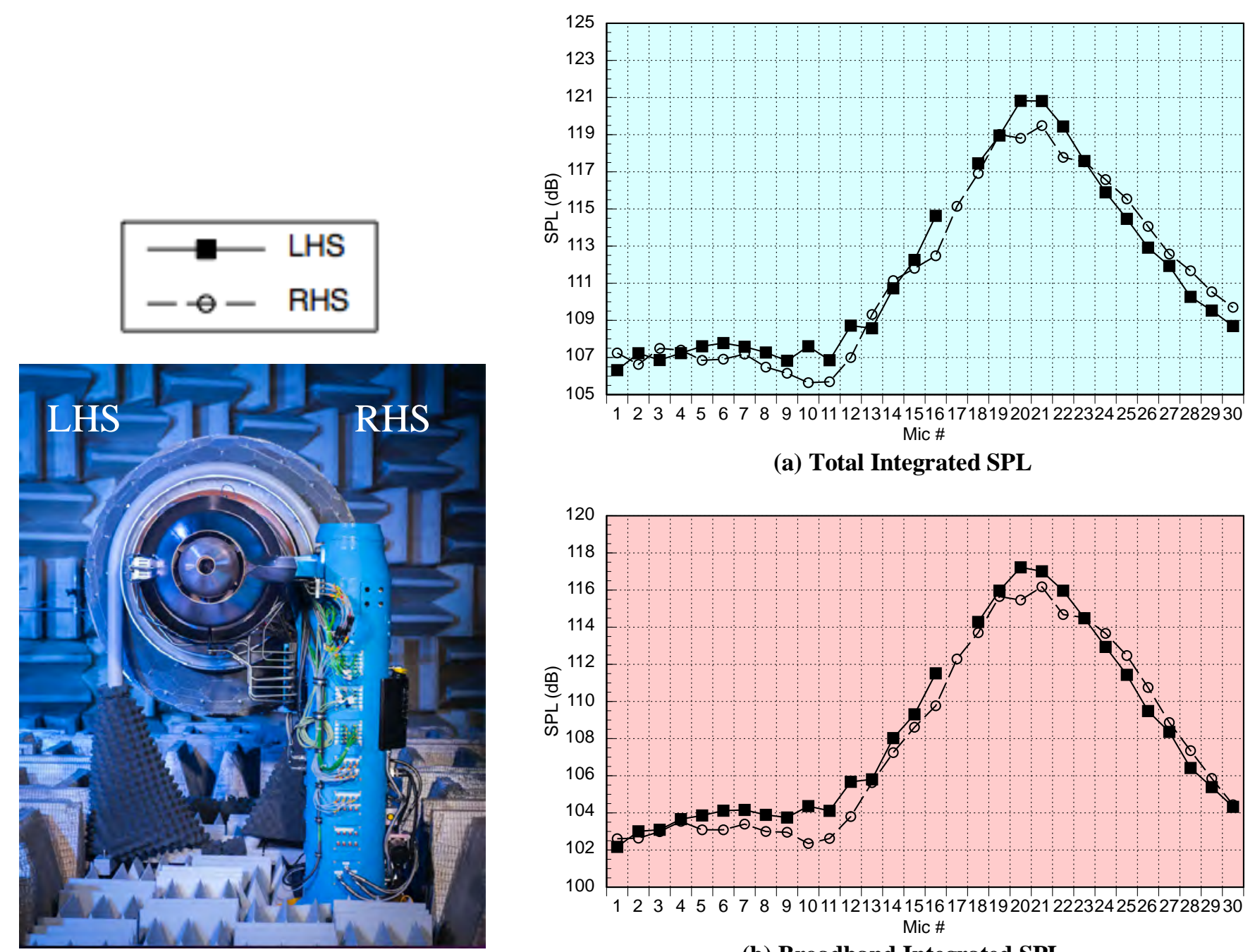

(a) Total Integrated SPL

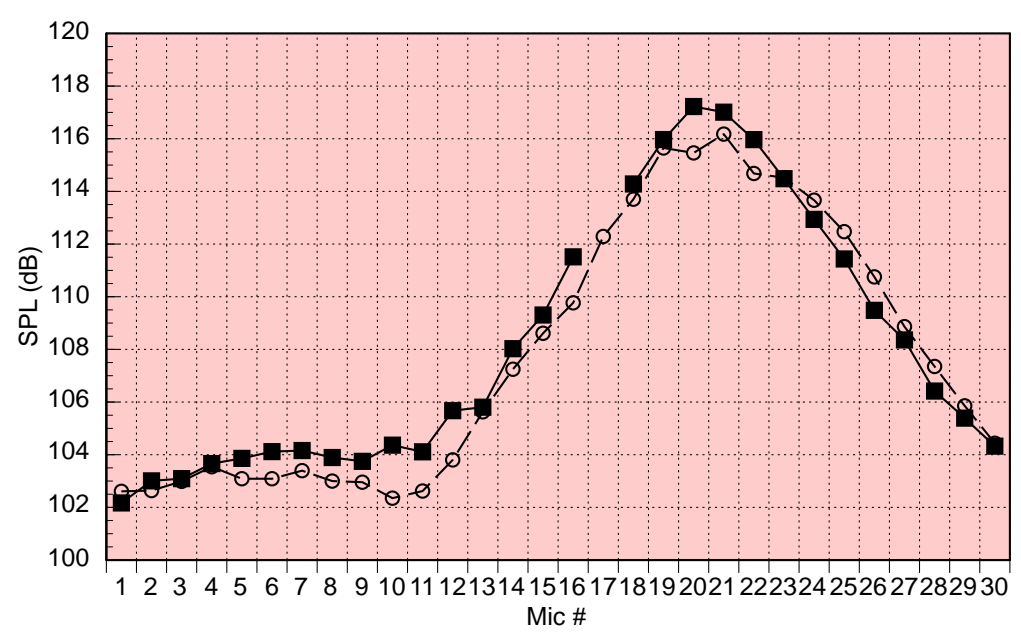

(b) Broadband Integrated SPL

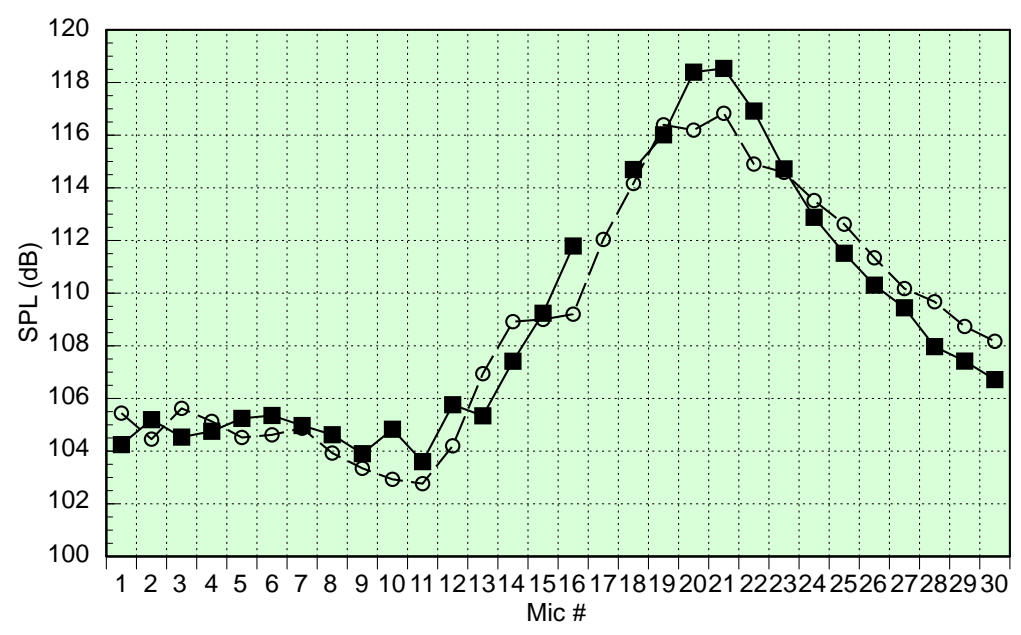

s(c) Tonal Integrated SPL

Figure 22. Acoustic Directivity of DART LHS and RHS as Measured by Linear Array: 92.5\% RPMc-Fan 

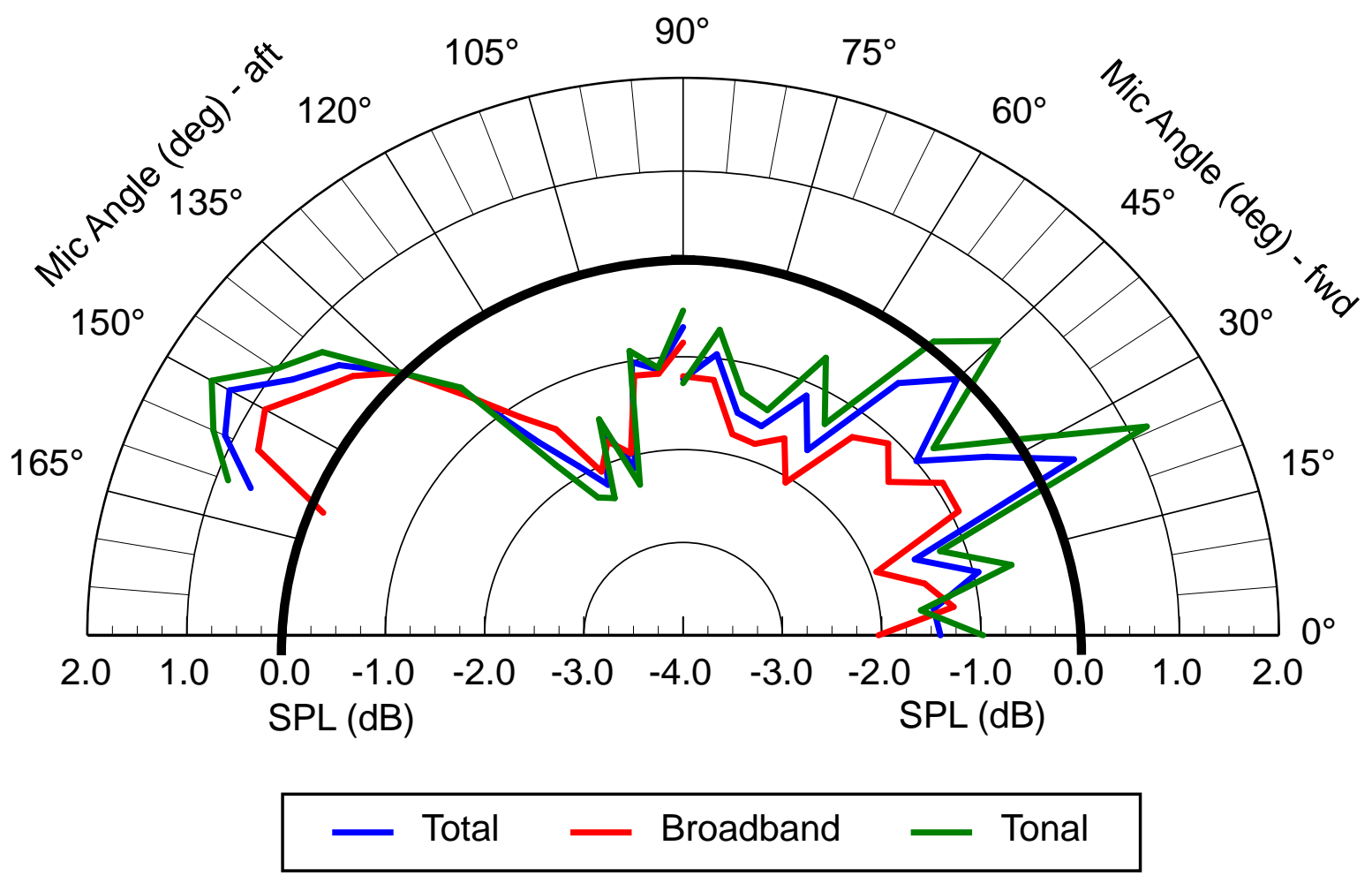

(a) Circular Array

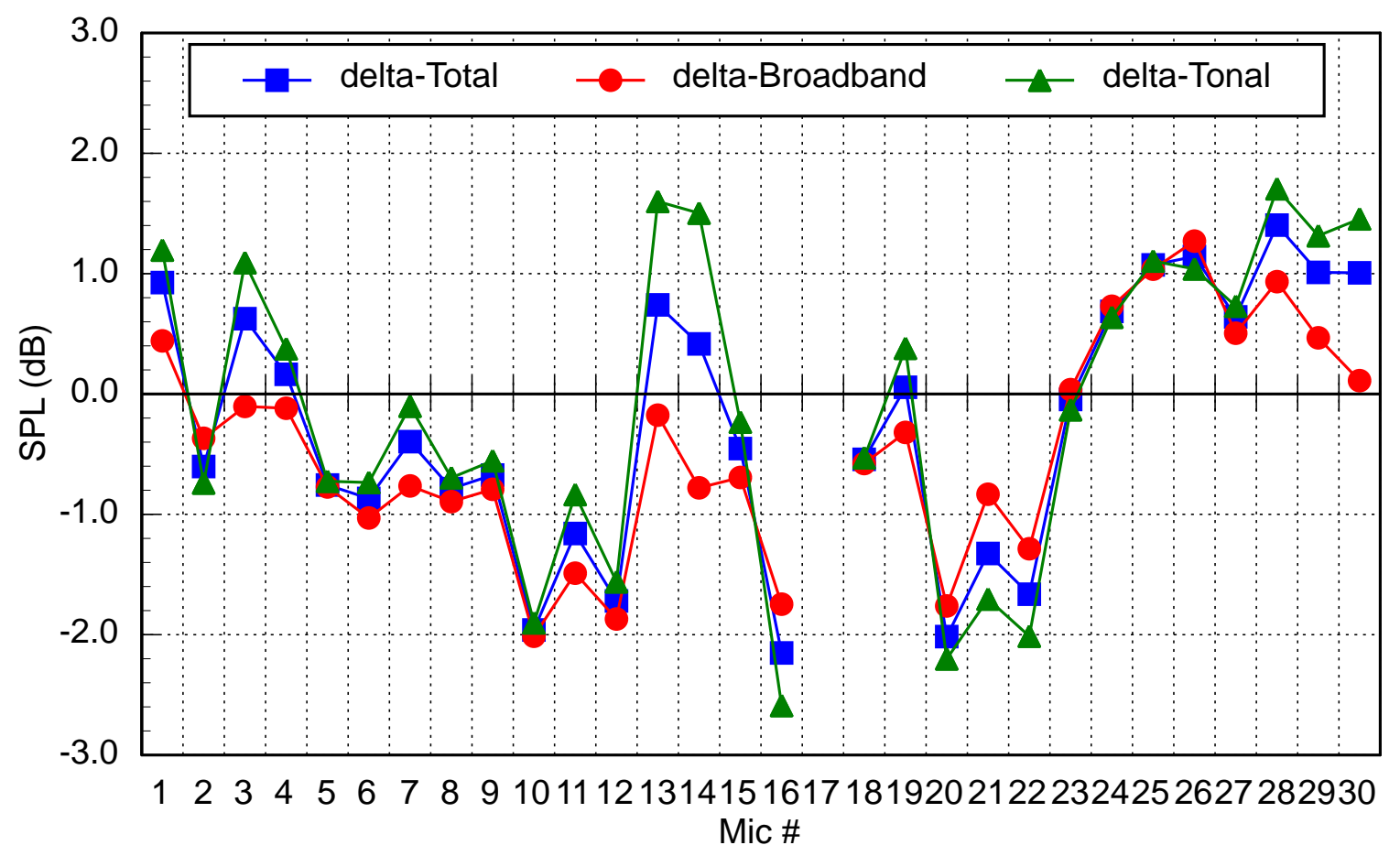

(b) Linear Array

Figure 23. Acoustic Directivity Differences of DART LHS and RHS (Both Arrays - referenced to LHS): 92.5\% RPMc-Fan 


\section{CONCLUSIONS}

The NASA Glenn Research Center's DGEN Aeropropulsion Research Turbofan (DART) test rig was integrated and tested in the NASA Glenn Aero-Acoustic Propulsion Laboratory. The acoustic signature of the DGEN380 turbofan engine over its operating range was presented in this paper. Farfield directivities from multiple independent microphone arrays locations, with differing geometric characteristics, were presented and in particular the acoustic symmetry noted. A proven tone-separation technique provided tonal and broadband analysis of a turbofan engine with two independent shafts.

The DART was noted to have multiple interaction tones between the fan and compressor as a result of the dualspool configuration. The turbine tones were dominant in the aft and exhibited the classic hay-stacking characteristic in the spectra resulting from propagation through the shear layer. These interaction tones were isolated from the spectra and evaluated independently. The symmetry of the acoustic directivity was measured and determined to not preclude testing in an environment permitting only pylon-side acoustic measurements. No significant differences were noted in the comparison of the acoustic measurements between the two locations with-in Aero-Acoustic Propulsion Laboratory.

The DART can be used as a test bed for noise reduction concepts, source diagnostics, and aero-propulsion code validation in support of the NASA Aeronautics strategy.

\section{ACKNOWLEDGMENTS}

This work was performed with support from NASA's Advanced Air Transport Technology Project. The author would like to express his appreciation for the efforts of the T-FOME staff at the Aero-Acoustic Propulsion Laboratory. Sincere appreciation is due to Price Induction, SA, for their exceptional partnership in integrating their DGEN380 into the DART system. A special acknowledgement is extended to memory of Benoit Bayon.

\section{REFERENCES}

${ }^{1}$ D.L. Sutliff, C.A. Brown, B.Bayon, B., and D. Sree, "Farfield Acoustic Characteristics of the DGEN380 Turbofan Engine as Measured in the NASA Glenn Aero-Acoustic Propulsion Laboratory", AIAA-2016-3006.

2 J.J. Berton, "System Noise Prediction of the DGEN380 Turbofan Engine", AIAA 2015-2516, 21st AIAA/CEAS Aeroacoustics Conference, Dallas, Texas , 22-26 June, 2015. Also, Journal of Aircraft, Volume 53, Issue 6, 2016. ${ }^{3}$ B.A. Cooper, "A Large Hemi-Anechoic Chamber Enclosure for Community-Compatible Aeroacoustic Testing of Aircraft Propulsion Systems", Journal of the Institute of Noise Control Engineering of the USA, Jan/Feb 1994.

${ }^{4}$ D. Sutliff, "The Advanced Noise Control Fan: A 20 Year Retrospective", $20^{\text {th }}$ Workshop of the Aerospace Specialists Committee of the CEAS/Measurements Techniques and Analysis Methods for Aircraft Noise, 7-8 Sept 2016, 201 GRC-E-DAA-TN32659.

5 "C.A. Brown and D.L. Sutliff, "DGEN Aeropropulsion Research Turbofan (DART): Projecting Acoustic Data to 1-Foot-Lossless", AIAA-2018-

${ }^{6}$ D. Sutliff, "Acoustic Directivity and Insertion Loss Measurements of Advanced Liners installed the Inlet of the DGEN Aero-propulsion Research Turbofan," AIAA-2008-

${ }^{7}$ D. Sree, "A novel signal processing technique for separating tonal and broadband noise components from counterrotating open-rotor acoustic data", International Journal of Aeroacoustics, vol. 12, no. 1+2, pp. 169-188, 2013.

${ }^{8}$ D. Sree and D.B. Stephens, "Tone and Broadband Noise Separation from Acoustic Data of a Scale-Model CounterRotating Open Rotor", in 20th AIAA/CEAS Aeroacoustics Conference, Atlanta Georgia, 16-20 June, 2014.

${ }^{9}$ N.A. Crumpsty, "Sum and Difference Tones from Turbomachinery", Journal of Sound and Vibration, 32(3):383386, 1974.

${ }^{10}$ D.L. Sutliff, "Interaction and Scattered Mode Measurement in a Mixed Bypass/Core Duct with Multiple Rotating Sources", International Journal of Aeroacoustics, Vol. 16, Issue 7-8, 2017.

${ }_{11}$ D.L. Sutliff, Konno, K.E., and Heidelberg, L.J., "Duct Mode Measurements on the TFE731-60 Full Scale Engine", NASA TM-2002-211573, AIAA-2002-2564.

${ }^{12}$ Assessment of NASA's Aircraft Noise Prediction Capability, Milo D. Dahl, editor; NASA/TP-2012-215653, July 2012. 